\title{
TRANSFORMACIÓN DE LAS FORTIFICACIONES EN EL NORTE DEL CAMINO REAL DE TIERRA ADENTRO EN MÉXICO: EL CASO DEL PRESIDIO DE EL PASAJE ${ }^{[*]}$
}

\author{
TRANSFORMATION OF THE FORTIFICATIONS LOCATED NORTH OF THE CAMINO REAL DE \\ TIERRA ADENTRO IN MEXICO: THE CASE OF EL PASAJE PRISON
}

\author{
ROBERTO CARRILLO ACOSTA ${ }^{(* \star)}$ E IRMA CASTILLO RUIZ $Z^{[* \star *}$ \\ Fecha de recepción: 18 de abril de 2017 \\ Fecha de aprobación: 14 de agosto de 2017
}

\section{RESUMEN}

Las investigaciones sobre las fortificaciones en el norte de Nueva España son escasas. Además, aunque hay escritos aislados sobre algunas fortificaciones, no se han realizado estudios que de manera integral hagan un seguimiento de cada recinto fortificado. El Camino Real de Tierra Adentro, motivo de este escrito, alberga un inmenso testimonio de los diversos procesos históricos que en su tendido se forjaron. Dicho testimonio se traduce en una gama de bienes patrimoniales que fueron construidos individual y colectivamente a lo largo de tres siglos. Su transformación da cuenta del conocimiento heredado de técnicas o modelos constructivos, y de estrategias de ocupación, lo cual le imprime un sentido de permanencia en el tiempo.

\section{PALABRAS CLAVE}

Fortificaciones, Camino Real de Tierra Adentro, presidio de El Pasaje

\section{ABSTRACT}

Investigations about the fortifications of northern New Spain are scarce. Besides, even though there are isolated writings on some types of fortification, no studies have been carried out that comprehensively track each fortified enclosure. The Camino Real de Tierra Adentro, the reason for this article, has left us an immense testimony of various historical processes forged in it. This testimony translates into a range of patrimonial assets that were built individually and collectively over the course of three centuries. Its transformation gives an account of the inherited knowledge of techniques or constructive models, and of the occupation strategies, which impress on it a sense of permanence in time.

\section{KEYWORDS}

Fortifications, Camino Real de Tierra Adentro, El Pasaje prison

(*) El presente escrito forma parte de una investigación de Carrillo Acosta para la obtención del grado de doctor en Historia por la Universidad Autónoma de Zacatecas (UAZ), 2009-2012, asesorada por T. Hillerkuss Finn; de sus proyectos titulados Transformación del Paisaje en el Camino Real de Tierra Adentro: Fortificaciones y Patrimonio en el Septentrión, Siglos XVII y XVIII y Apropiación, Uso y Transformación de Caminos Militares en el Norte de la Nueva España, Durante los Siglos XVII Y XVIII, realizados en la UAZ; y del proyecto de Castillo Ruiz EI Patrimonio Cultural en el Itinerario Cultural del Camino Real de Tierra Adentro en su Travesía por el Estado de Zacatecas: el Caso de la Noria de San Pantaleón, en Sombrerete. Investigación, Documentación y Gestión para su Preservación, del Programa para el Desarrollo Profesional Docente (PRODEP-UAZ), en el marco del grupo de investigación Historia e Interpretación del Patrimonio, donde ambos autores participan.

$\left({ }^{* *}\right)$ Licenciado, maestro y doctor en historia por la UAZ, fue responsable de la biblioteca especializada en Antropología e Historia "Camino Real de Tierra Adentro", resguardada por el Instituto Nacional de Antropología e Historia de Zacatecas durante el periodo 2001-2009. Es docente investigador de la licenciatura en Historia de la UAZ desde 2014 a la fecha. Ha realizado diversas publicaciones y conferencias en torno a dichos temas. Contacto: robertohistory@hotmail.com

${ }^{* * *}$ Licenciada en Historia por la UAZ (2008). Maestra y doctora en Historia por el Colegio de Michoacán, A. C. (2010 y 2014, respectivamente). Las líneas de investigación que ha desarrollado giran en torno al arte y la religiosidad popular en Zacatecas durante los siglos XIX y XX; manifestaciones religiosas, santuarios y peregrinaciones en el centro y norte de México; gestión cultural; políticas públicas de la cultura y el patrimonio cultural en el estado de Zacatecas; y educación patrimonial. Contacto: faviola.cr@gmail.com 
devenir Vol. 4, N8, JULIO - DICIEMBRE 2017, PP. 97-122 - EstudIOS | ISSN 2312-7562 | E-ISSN 2616-4949

UNIVERSIDAD NACIONAL DE INGENIERÍA, LIMA

Entre las principales preocupaciones de esta investigación se encuentra el proceso de ocupación de la Nueva Vizcaya por parte de los españoles, cuya conformación abarcaba, principalmente, Durango, Chihuahua, Sonora y Sinaloa. No obstante, fue muy cambiante, y en cierto tiempo incluyó las Californias e incluso Nuevo México, este último hasta que se instauró como un reino propio. La intención es abordar el asunto desde un enfoque innovador, que consiste en concentrar la atención en el espacio geográfico que demarcó el tendido del Camino Real de Tierra Adentro, área donde se establecieron cuatro presidios durante los siglos XVII y XVIII: El Pasaje', El Gallo, Cerro Gordo y Conchos, ${ }^{2}$ los cuales se han identificado como presidios del Camino Real, pues estaban orientados a proteger a los pasajeros, en específico a los arrieros comerciantes.

Además, estos presidios cumplían la función de pacificar el territorio para que reales de minas ${ }^{3}$, haciendas de campo o ganaderas, misiones y villas fueran apropiándose de la región y conformándose como poblaciones más o menos estables, ya que las permanentes incursiones y rebeliones de las naciones indígenas dificultaban una ocupación firme. Se supone que ante esta situación los soldados presidiales hacían incursiones para volver a pacificar el territorio conquistado; en realidad, estaban más dedicados a brindar protección en los caminos y la frontera del norte.

Otra manera de brindar sentido de permanencia o de ocupación definitiva fue el disponer que los presidios, al mismo tiempo que se mantenían como puestos militares de avanzada y defensa, se fueran convirtiendo en poblaciones, a partir de los grupos de soldados de cada guarnición y sus familias. Ese fue el caso del presidio llamado El Pasaje, ubicado en el actual estado de Durango, al norte del país.

\section{Camino Real de Tierra Adentro}

Después de la conquista de México, los exploradores españoles se dirigieron hacia el norte en busca de territorios para establecer su ocupación: minas, haciendas, misiones, presidios. Mediante sus desplazamientos fueron estableciendo caminos, senderos, brechas y hasta verdaderas rutas, que conformaron una red vial que atravesaba prácticamente todo el país -se observaba desde la ciudad de México hasta San Juan Pueblo, en Nuevo México-, y que muy pronto recibiría el nombre de Camino Real de Tierra Adentro ${ }^{4}$ (Crespo-Francés, 1998, p. 21) (ver Figura 1).

El proceso de ocupación que iría consolidando los caminos, no solo se experimentó en el norte del continente americano, sino que también se observó en otros continentes. Los caminos adquirieron gran relevancia tanto en los procesos de ocupación como en el mantenimiento de una red de comunicación permanente que permitiría formar

Figura 1. Camino Real de Tierra Adentro. Elaborado sobre la base de Camino Real de Tierra Adentro (pp. 15, 57, 117 y 159), por E. Martínez, 2006, D. F., México: CONACULTA - INAH - Grupo Desea.
1. Llamado también Nuestra Señora de la Purísima Concepción de El Pasaje. Para efectos prácticos, en el texto únicamente se le denominará El Pasaje.

2. También en esa región se ubicaba el presidio de Santiago de Mapimí, aunque un poco al Este, rumbo a Saltillo, en el desierto conocido como Bolsón de Mapimí. Dicho presidio queda fuera del trazo del Camino Real, y no es mencionado o tomado en cuenta en las escoltas de pasajeros que se formaron ni en el cordón defensivo de presidios del Camino Real.

3. Los reales de minas eran espacios territoriales cuya principal actividad era la minería, es decir, la extracción de metales preciosos como oro, plata, estaño, entre otros. México se caracterizó por el gran auge en la explotación de plata; por ello, algunos caminos se llegaron a denominar caminos de la plata. Los españoles, además de buscar la conversión o evangelización de los indígenas, trazaron sus exploraciones en busca de estos minerales, fundando poblaciones mineras o simples emplazamientos mineros, llamadas haciendas de minas o reales de minas.

4. Camino real se refiere al camino del rey, término que se aplicaba a todas las vías de comunicación principales del reino, tanto en España como en las provincias del Nuevo Mundo, mientras que tierra adentro se refiere a aquel camino que después de la ciudad de México se enfilaba hacia el norte de la Nueva España hasta Nuevo México, ruta que contenía a su vez el Camino de la Plata, tramo de la misma ruta que llegaba desde México hasta Zacatecas. Además, tierra adentro también se refería al recorrido por la frontera. 



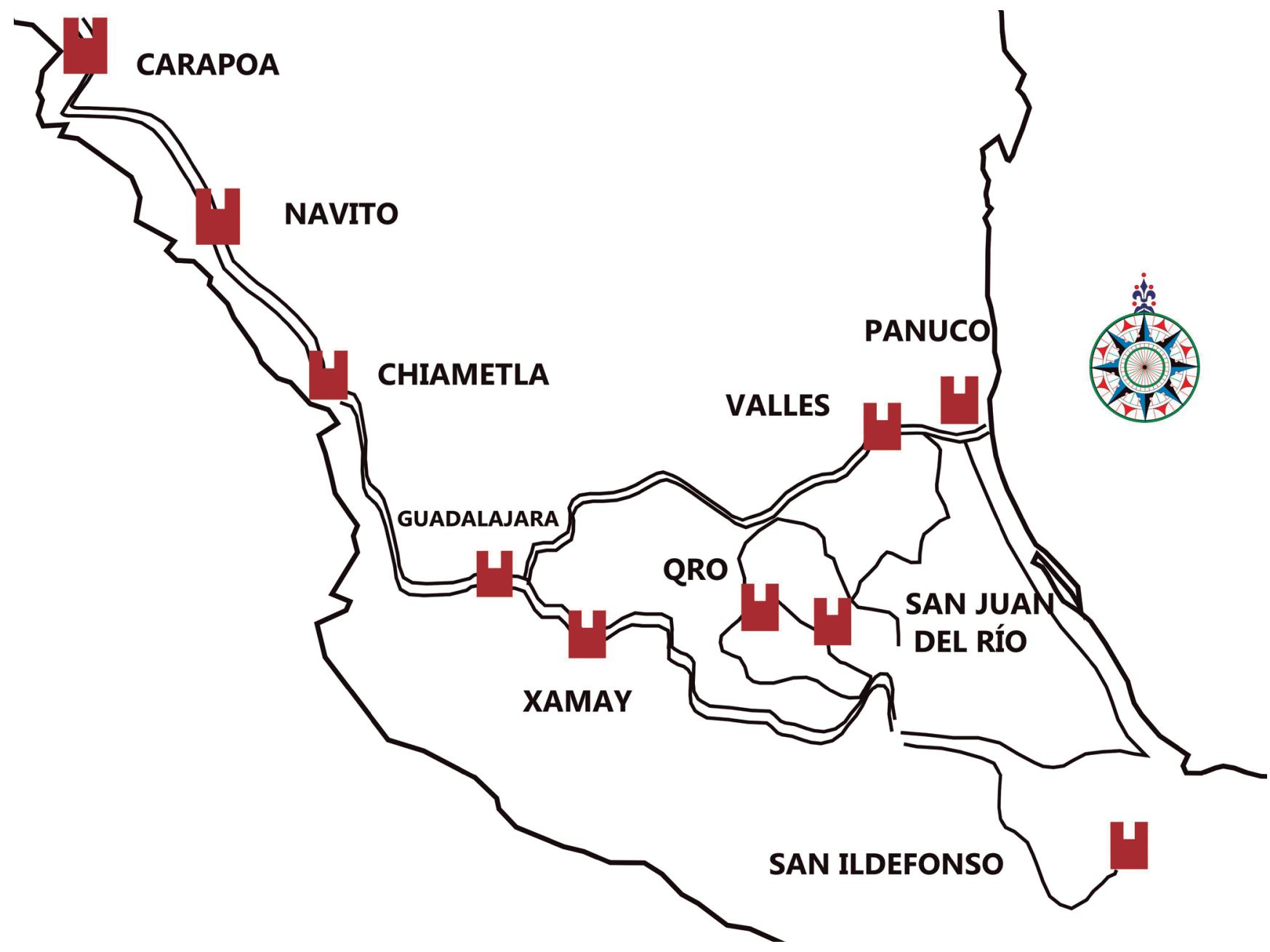

Figura 2. Presidios en el Valle de México. Diseño por R. Carrillo Acosta, sobre la base de El presidio en México en el siglo XVI (p. 131), por L. Arnal, 1998, D. F., México: Universidad Nacional Autónoma de México. enclaves urbanos, desde el cual se presenció la formación de medios de subsistencia económica, tales como estancias, haciendas, presidios, misiones y albergues.

Tal fue la trascendencia de dichos caminos, que llegaron a formar parte indispensable de la vida cotidiana de la población. Con el tiempo, fueron reconocidos como históricos, y se les asignó el distintivo de rutas, lo que los convirtió en verdaderas claves de interpretación para la construcción del territorio. Ese fue el caso de la Ruta de la Seda en China, de tipo comercial; de la Vía de la Plata, que sirvió para unificar el occidente de Hispania y continuó siendo recorrida en la Edad Media: en torno a ella circulaban guerreros y ganado, se establecían ferias y mercados; del Camino de Santiago, considerado la ruta de la fe y la caridad en el Medioevo; entre otras más. Lo mismo sucedió en el caso del Camino Real de Tierra Adentro en México, que se convirtió en una de las principales arterias de tráfico comercial y cultural.

\section{Fortificaciones}

El origen del término fortificación se encuentra en las palabras latinas fortis (fuerte) y facere (hacer), que juntas significan "hacer fuerte", es decir, capaz de resistir el ataque del enemigo, que por lo regular era superior tanto en número como en fuerza. La idea era mantener la posición y posesión de un sitio o territorio instalando obstáculos de manera estratégica y planeada. Pero, ¿cómo se lograba este objetivo?, ¿cómo se logra- 
ba fortificar un territorio? Por medio de la guarnición del sitio, en dos aspectos: por un lado, construyendo el edificio con todas las disposiciones de una fortificación; por el otro, mediante la implementación de una guarnición, específicamente de soldados.

Esto sucedió con casi todas las edificaciones fortificadas de orden militar, que son las que se abordan en esta investigación. Las había consideradas permanentes y eventuales. En cuanto a las segundas, no necesariamente tenía lugar la guarnición de soldados, pues estos podían permanecer o no. Generalmente, ello obedecía a que eran
Figura 3. Presidios del Camino Real en Zacatecas. Diseño por R. Carrillo Acosta, sobre la base de "Génesis del Presidio como Institución Fronteriza 1569-1600", por P. Wayne Powell, 1982, abril, The Western Historical Quarterly. Recuperado de http://revistas.unam. $\mathrm{mx} / \mathrm{index} . \mathrm{php} / \mathrm{ehn/article/viewFi-}$ le/3309/2864

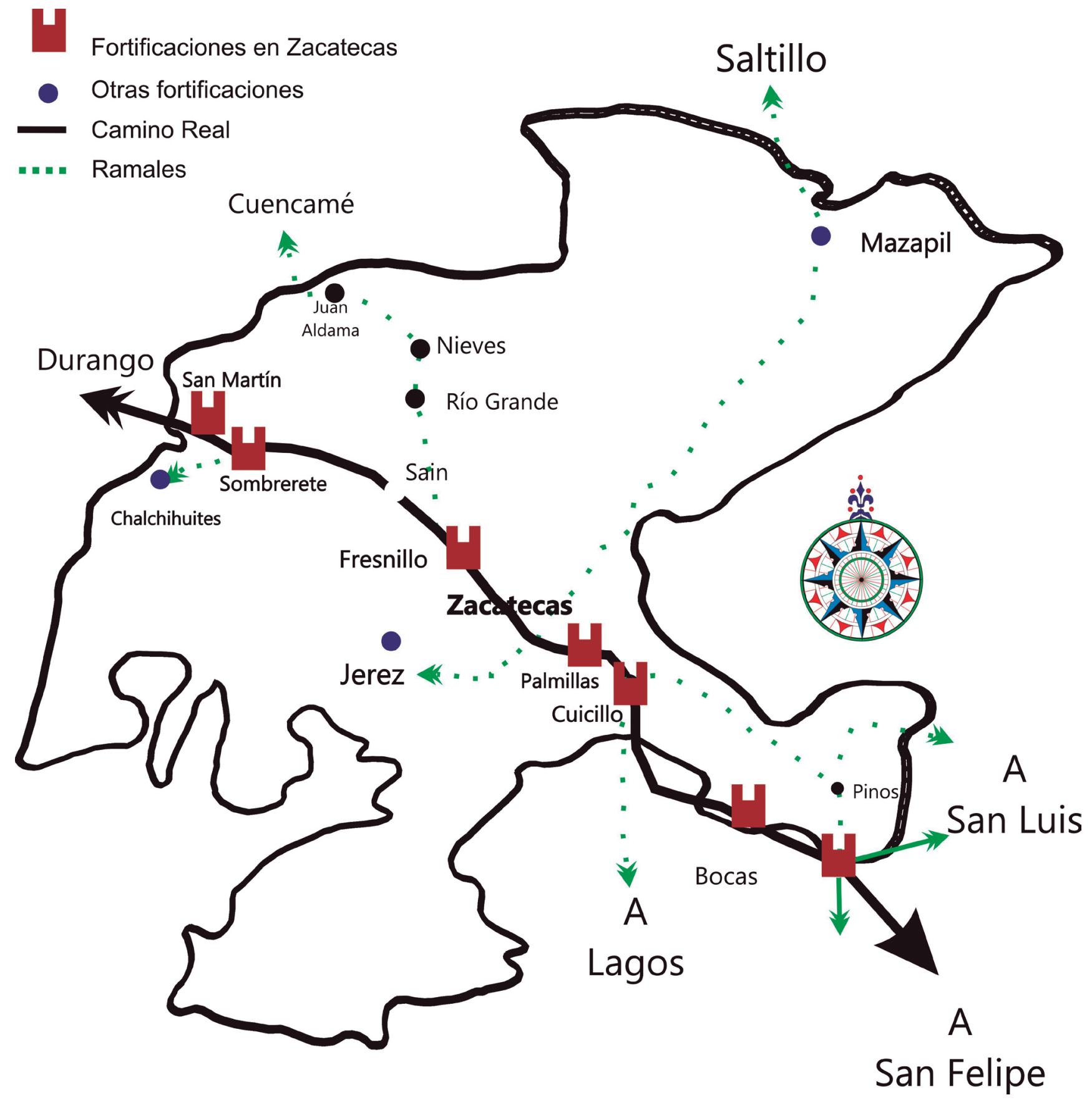




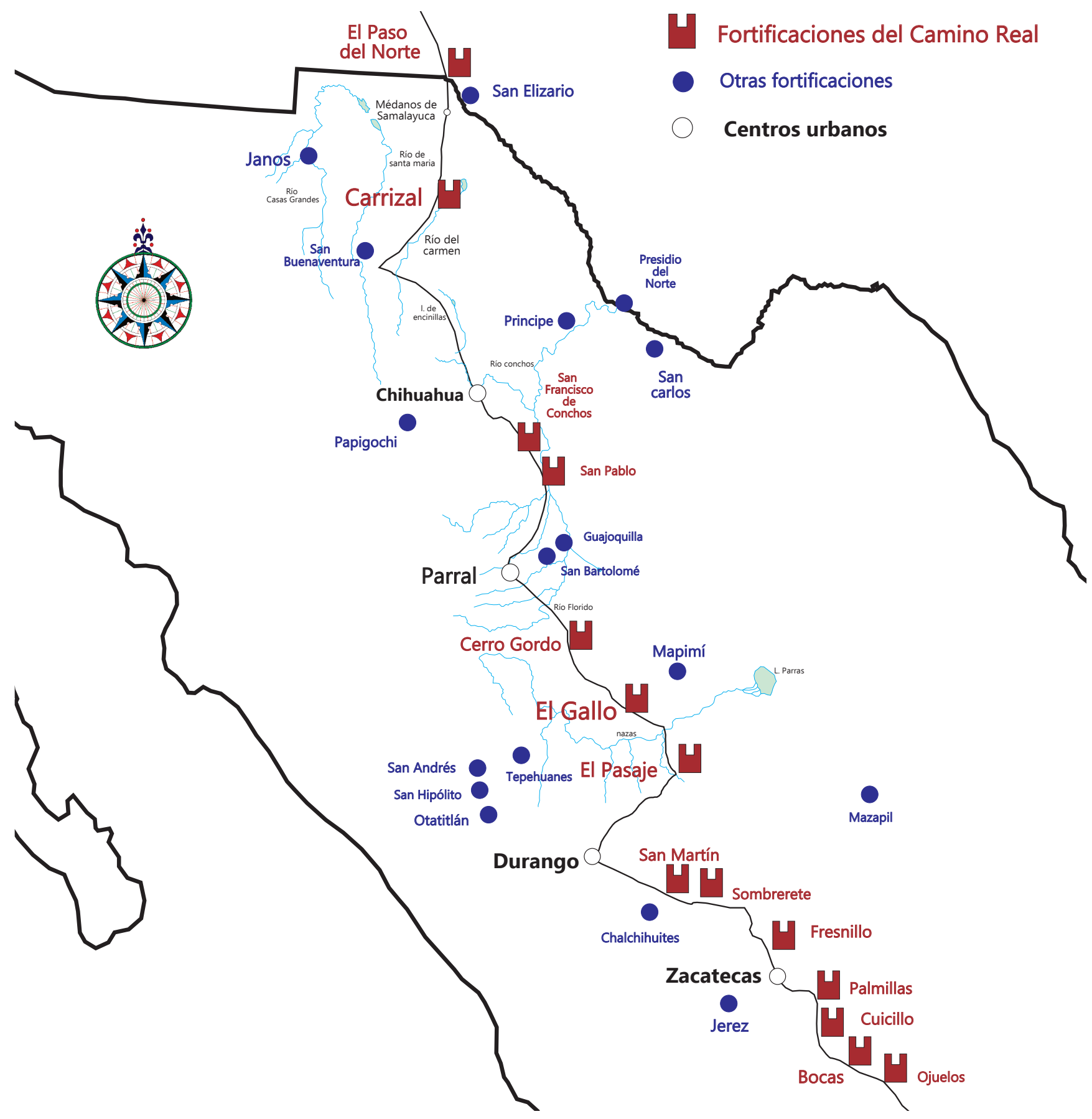

Figura 4. Fortificaciones en el norte del camino real. Diseño por R. Carrillo Acosta, sobre la base de Presidio y población indígena en la Nueva Vizcaya. Siglos XVII y XVIII, por A. Guevara Sánchez, 2011, Michoacán, México: Universidad Michoacana de San Nicolás de Hidalgo, puestos de control o de supervisión, o puestos fortificados para defender una posición: al lograr el objetivo, la posición se abandonaba.

En el México colonial existía una gran variedad de fortificaciones, de sitios o edificios fortificados. Una primera gran clasificación se determina de acuerdo con las estrategias de ocupación que implementó el Imperio español: haciendas, misiones y presidios. Los últimos, de carácter y función militar, son de los que se ocupará esta investigación. Los presidios se ubicaban dentro de una clasificación mayor de fortificaciones, que se ha llamado arquitectura militar. 


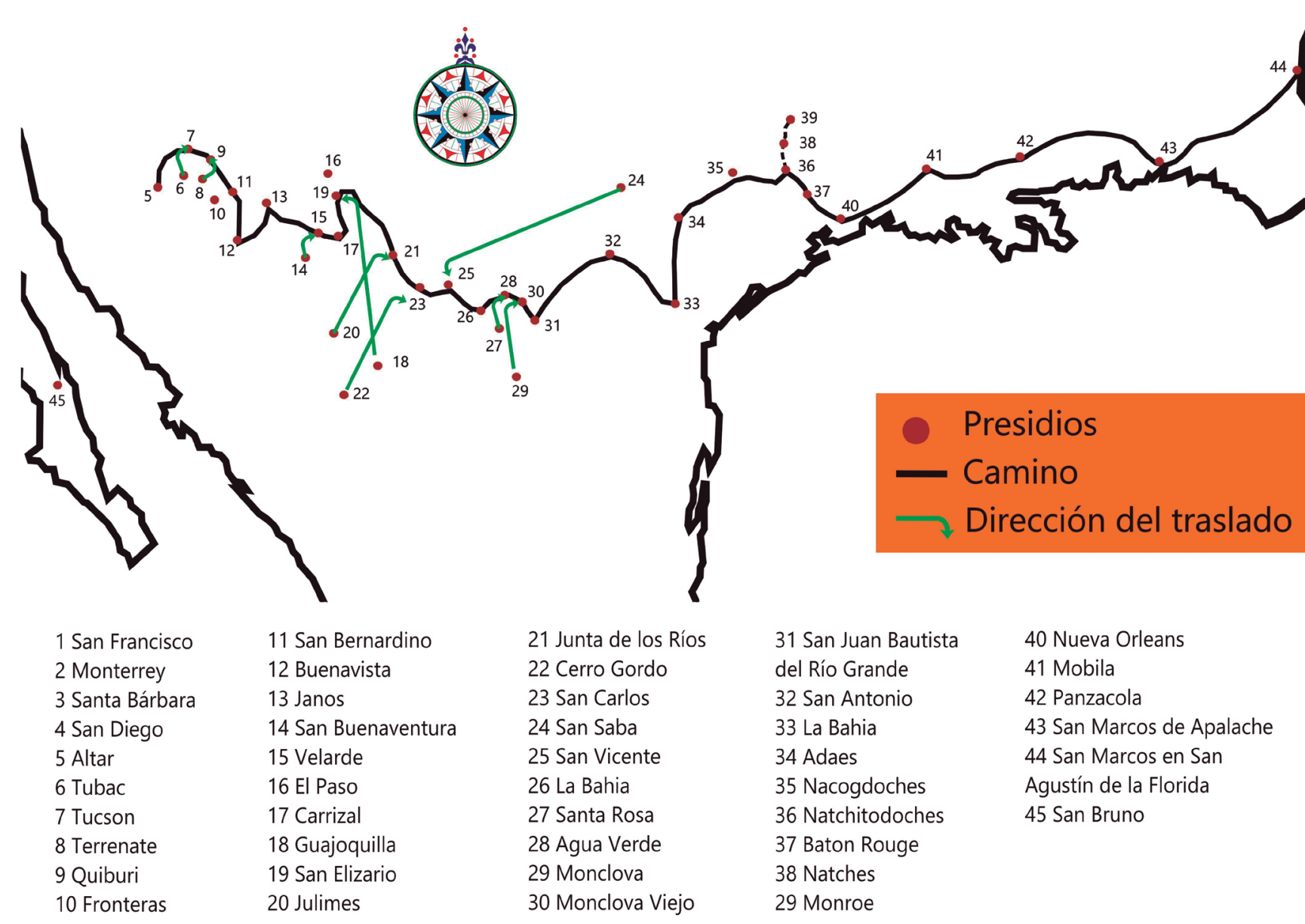

En orden de importancia militar, pero sobre todo por sus dimensiones, dentro de la arquitectura militar se cuentan las fortalezas, fuertes, fortines, reductos y casamatas. El promedio de tamaño observado en las fortificaciones era de 15,000 $\mathrm{m}^{2}$, pero también las había muy pequeñas o muy extensas, que alcanzaban incluso los $122,000 \mathrm{~m}^{2}$. Los presidios calzaban en la clasificación de fortalezas, entre las fortificaciones de mayor tamaño.

\section{Presidios}

Los presidios se establecían a la vera de los caminos, aunque la mayoría de las veces, más bien, era su construcción la que iba abriendo y configurando los caminos, pues se trataba de puestos de avanzada militar, que se ubicaban en sitios con afluentes de agua, muchos siguiendo el descubrimiento de minas o simplemente instalándose en la frontera de los poblados, pues su función defensiva residía básicamente en la protección de poblados y, en menor medida, de los caminos y de la frontera. Fue gracias a ellos que se brindó sentido de pertenencia a las poblaciones, es decir, el arraigo de identidad, pero sobre todo de permanencia. Sin embargo, en el caso particular del Camino Real de Tierra Adentro, la prioridad de los presidios fue resguardar los caminos (ver Figura 2).

Esto sucedió en los siglos XVI y XVII, pero ya en el XVIII se le agregó una nueva función a los presidios: formar poblaciones, aun durante los tiempos de conflicto. Por ello, en las ordenanzas se disponía que las familias de los soldados se establecieran en las cercanías de cada presidio, lo cual sucedió sobre todo en el norte del país. También se dispuso que, al lograr la pacificación de cada región, se fundaran poblaciones civiles
Figura 5. Formación de la línea de presidios. Diseño por R. Carrillo Acosta, sobre la base "El sistema presidial en el septentrión novohispano, evolución y estrategias de poblamiento", por L. Arnal, 2006, 1 de agosto, Scripta Nova, Revista Electrónica de Geografía y Ciencias Sociales. Recuperado de http://www.ub.edu/geocrit/sn/sn218-26.htm 
en los mismos, integradas por soldados y sus familias, ya sin actividades militares. Entonces, el resto de soldados emigrarían a otros lugares de frontera donde se necesitara brindar seguridad militar; de esta manera, se fueron recorriendo las guarniciones, los presidios y la misma frontera hacia el norte, cada vez que se pacificaba una región. Durante el siglo XVI esta dinámica fue la norma, y tras pacificarse la región del valle de México, la frontera avanzó hacia la Nueva Galicia, cuyo límite era el actual Zacatecas, además de integrase por Guadalajara y Nayarit (ver Figura 3).

A finales del mismo siglo XVI y principios del siguiente se logró su pacificación, y la frontera se desplazó hasta la Nueva Vizcaya, en Nuevo México (ver Figura 4). Ya para el siglo XVIII, se desplazaron las guarniciones (soldados) de todos los presidios del país y la frontera norte a Nuevo México, con lo cual quedó casi establecida la frontera actual entre México y los Estados Unidos de América (ver Figura 5).

\section{Arquitectura de presidios}

El modelo que se utilizó para la construcción de los presidios durante las primeras incursiones españolas se continuó empleando en las exploraciones rumbo al norte. El presidio era el recurso que aseguraba la avanzada y la ocupación del espacio por medio de la fundación de villas, ciudades, reales de minas, misiones y haciendas. Lo que variaba en cada región eran los materiales empleados y los espacios que integraban estas fortificaciones, es decir, las dependencias y los mismos servicios que se ofrecían, lo cual correspondía en gran medida a la dimensión de los mismos, aunque por lo regular eran de gran tamaño, por encima de los $10,000 \mathrm{~m}^{2}$. Por otro lado, en muchos casos, debido a la premura de su utilización, se construían de prisa y sin un plan de edificación (Arnal, 1998).

En todos los presidios se hizo uso de muros defensivos. Los primeros que se levantaron consistieron en palizadas con troncos hincados o clavados. Más adelante, se construyeron a base de piedra, e incluso se reutilizaron los muros de las construcciones prehispánicas. Esto sucedía con mayor frecuencia en la elaboración de los cimientos y en las esquinas de los muros (Arnal, 1998). Según Max Leon Moorhead (2012), la ausencia de vestigios de los primeros presidios en la actualidad indica la fragilidad de las primeras construcciones. Hasta el siglo XVIII se reemplazaría el material, e incluso se reforzarían con contrafuertes de mampostería (Guevara Sánchez, 2011, p. 229). No obstante, cabe señalar que aún no hay suficientes estudios arqueológicos que den cuenta de ello.

Ante la ausencia en la región de una piedra resistente, se tuvo que recurrir a la fabricación de grandes cantidades de adobe. Para ello se mezclaba barro con hierbas secas y luego se secaban al sol. Para acelerar la producción se utilizaba la técnica del encofrado, que consistía en instalar tablones paralelos y rellenar el espacio entre ambos con la mezcla de barro. El resultado era una pieza que permitía levantar muros altos, pesados y muy fuertes. Además, el adobe resultaba óptimo para cualquier clima, pues permitía que los edificios fueran tibios en invierno y frescos en el verano (Guevara Sánchez, 2011, pp. 230-231).

La dimensión o extensión de los presidios variaban mucho: los había de 60 × 60 metros, correspondiente a $3,600 \mathrm{~m}^{2}$; y de $350 \times 350$ metros, equivalente a $122,500 \mathrm{~m}^{2}$. También variaba el espesor de los muros, pero como mínimo debían tener un metro de ancho para ser resistentes a los impactos de flechas o balas. Se podían incorporar a los muros troneras ${ }^{5}$ reforzadas con torreones, y también pasos de ronda ${ }^{6}$ hechos de madera, lugar donde los soldados tenían mejores ángulos de tiro. En algunas ocasio-

\footnotetext{
5. Una tronera de presidio es una excavación, a manera de trinchera, un agujero que se ubicaba inmediatamente después y afuera de las murallas de los presidios, bordeándolas.

6. Se trataba del techo de los presidios, que corría por toda la muralla, justo por donde transitaban los soldados, en este caso, especialmente aquel que hacía las veces de ronda o guardia.
} 


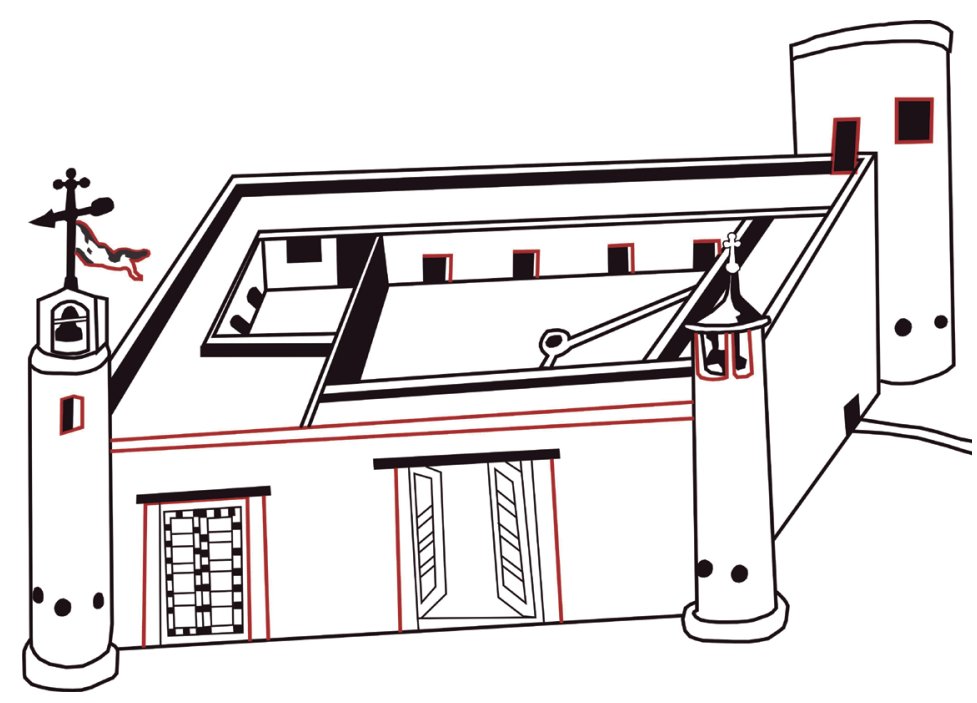

nes los muros llegaron a alcanzar los 3 metros de altura, por lo menos, siguiendo una forma cuadrada o rectangular, a manera de muralla (Arnal, 1998, pp. 216-217).

Por tratarse de construcciones defensivas, era extraño encontrar elementos de ornato, aunque sí se observaban muros aplanados en cuyos remates se pintaban dibujos geométricos. En algunas áreas, como las troneras, aspilleras y mirillas de las torres, se utilizaba la piedra labrada. Los techos se construían empleando madera, y se colocaba encima tejamanil, una especie de loza de tierra cocida llamada teja, y luego se cubría de terrado, que al final se sellaba con tierra o cal. Con el tiempo la edificación se podía ir modificando y reparando, incluso ampliando sus dimensiones. Eso fue lo que sucedió con los presidios del norte, en específico aquellos que se fueron instalando en el curso del Camino Real de Tierra Adentro (Arnal, 1998, p. 209).

Los presidios usualmente se construyeron empleando mano de obra indígena. Era muy frecuente que las obras fueran edificadas apresuradamente, ante la presencia inminente del enemigo, aunque también era común que se retrasaran por falta de adobe para los muros. En el último caso se recurría a las autoridades locales para que les facilitaran mayor número de mano de obra. Esto sucedió en la Nueva Vizcaya, durante la construcción del presidio de San Carlos en 1773; al retrasarse la obra, el alférez (oficial militar con grado menor que el teniente, que se ocupaba de la supervisión de las obras) exponía en su solicitud lo siguiente: "ocurría vuestra merced suplicándole se sirviese librar mandamiento para que se me entregasen quince indios que fabricasen el número de setenta mil adobes que considero necesarios para una perfecta conclusión" (Archivo Histórico Municipal de Chihuahua [AHMCH], 1773, f. 1). Más adelante, vuelve a extender la solicitud, pero ahora por el número de 30 indígenas Al final, las autoridades concluyeron lo siguiente:

Mando se verifique los recados necesarios para que mi lugarteniente del partido de Babonoyaba haga aprontar cincuenta hijos indios de los pueblos de Satevó, Babonoyaba, Guadalupe y la Joya para emplearlos en la fábrica material del nuevo Real Presidio de San Carlos, en donde se les dará el salario y ración acostumbrada y el buen tratamiento que previene su majestad... y conclusa la obra se retiren a sus respectivos pueblos. (AHMCH, 1773, f. 3 vuelta)

Dándole seguimiento a la petición, los tenientes del presidio se presentaron en dichos pueblos tras juntar nueve familias en el de Guadalupe, siete en el de Satevó, trece en el de la Joya y, finalmente, nueve independientes de dichos pueblos, es decir,
Figura 6. Modelo tridimensional de presidio. Diseño por R. Carrillo Acosta, sobre la base de sobre la base de El presidio (p. 247), por M. Moorhead, 2012, Chihuahua, México, Gobierno del Estado de Chihuahua.

Figura 7. Vista en planta de un presidio. Diseño por R. Carrillo Acosta, sobre la base de El presidio en México en el siglo XVI (p. 198), por L. Arnal, 1998, D. F., México, Universidad Nacional Autónoma de México. 
indígenas que llamaban "fugitivos viejos"y "enfermos", Ilevándolos por el Camino Real hasta el dicho presidio. Al final, se lograron reunir 38 familias, a pesar de que en algunos pueblos no había indígenas en condiciones de trabajar, y donde los había estos se dedicaban al cuidado de sus cosechas de trigo (AHMCH, 1773, f. 4). De esta manera, mientras se terminaba de construir, los soldados y el único capitán con el que contaban se resguardaban en tiendas de campaña y barracas (Moorhead, 2012, p. 121).

El techo de cada edificio estaba construido con polines de pino - un tipo de árbol característico de la región, que crecía en las sierras cercanas-, los cuales se cubrían con terrado 7 . De esa manera se evitaba que pudieran prenderse con el sol o que se pudiera incendiar el presidio en caso de ser sitiado. En algunos casos los muros eran recubiertos con aplanado ${ }^{8}$, lo cual aumentaba su resistencia; muchas veces, además, los muros sobresalían de la techumbre, para dar protección. Se podía subir a dicho techo utilizando escaleras de madera. Además, es muy probable que, aparte de las murallas, los presidios contaran con una valla exterior, fijada con postes de madera (Guevara Sánchez, 2011, pp. 230-231).

Algunos otros materiales utilizados en la construcción de los presidios se especifican en el informe de gastos presentado durante el año de 1784 sobre la fábrica o construcción del presidio de Guajoquilla. En él, se presentan los pagos por el contrato de un herrero, los cuales ascendían a 37 pesos y 5 reales. Sin duda se empleó para la construcción de las caballerizas, pozos, trojes, etc. En el informe también se incluyó la inversión de 18 pesos y 4 reales que se pagaron a un carpintero, así como el pago de 47 a otro, por lo que se entiende que había espacios en que utilizaban la madera, sobre todo, como se señaló antes, en los techos. Este es el caso de la casa de la pólvora y las trojes, las cuales ocuparon $20 \operatorname{cargas}^{9}$ de raja tableteada ${ }^{10}$. La madera también se utilizó para la elaboración de algunas puertas, ventanas, pasamanos, entre otras cosas (Archivo Histórico Municipal de Parral [AHMP], 1784, ff. 5-6).

Los presidios debían ser verdaderas fortalezas para poder contener las continuas incursiones de los indígenas enemigos, ya que no solo abrían la frontera para posibles nuevas fundaciones, sino que protegían las poblaciones cercanas ya establecidas, y defendían también a otros indígenas al resguardarlos en el interior de los mismos presidios.

\section{Modelos constructivos}

La historia permite observar la transformación de los presidios, que pasaron de ser puestos militares improvisados a convertirse en fuertes sencillos para, finalmente, a llegar a formar verdaderas guarniciones de grandes dimensiones, tanto en número de soldados como en tamaño arquitectónico, y llegaron incluso a configurar cordones o líneas de presidios defensivos. Las principales diferencias entre los presidios y los fuertes comunes era el tamaño de la edificación -los primeros eran más grandes-y también de su guarnición, que en el caso de los presidios era de carácter permanente.

Los primeros presidios se construyeron a manera de pequeños castillos, compuestos por una pared que formaba un perímetro cuadrangular, y en tres o cuatro de sus esquinas se ubicaban torres cilíndricas, a manera de miradores (ver Figura 6).

En el modelo de presidio que se observa en la Figura 6, las dos torres ubicadas al frente tenían funciones determinadas: desde una se custodiaba la entrada más grande

\footnotetext{
7. Término técnico para referirse al uso de tierra

8. El aplanado es una mezcla de arena, cal y cemento que se adosa a los muros, a manera de enjarre.

9. Carga podía referirse a una porción, montón o bulto de algún producto o mercancía, en este caso, de rajas.

10. No se ha determinado con exactitud su definición, pero se piensa pudieron ser tiras de madera o tablas.
} 


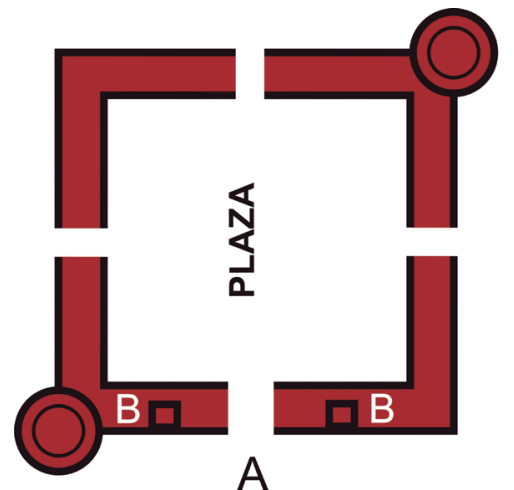

A. ENTRADA PRINCIPAL B. CUERPO DE GUARDIA

Figura 8. Presidio de El Gallo, 2016. Diseño por R. Carrillo Acosta, sobre la base de Relación del viaje que hizo a los presidios internos situados en la frontera de la América septentrional, perteneciente al rey de España, (pp. 61-62), por N. Lafora de, 1939, D. F., México: Pedro Robredo

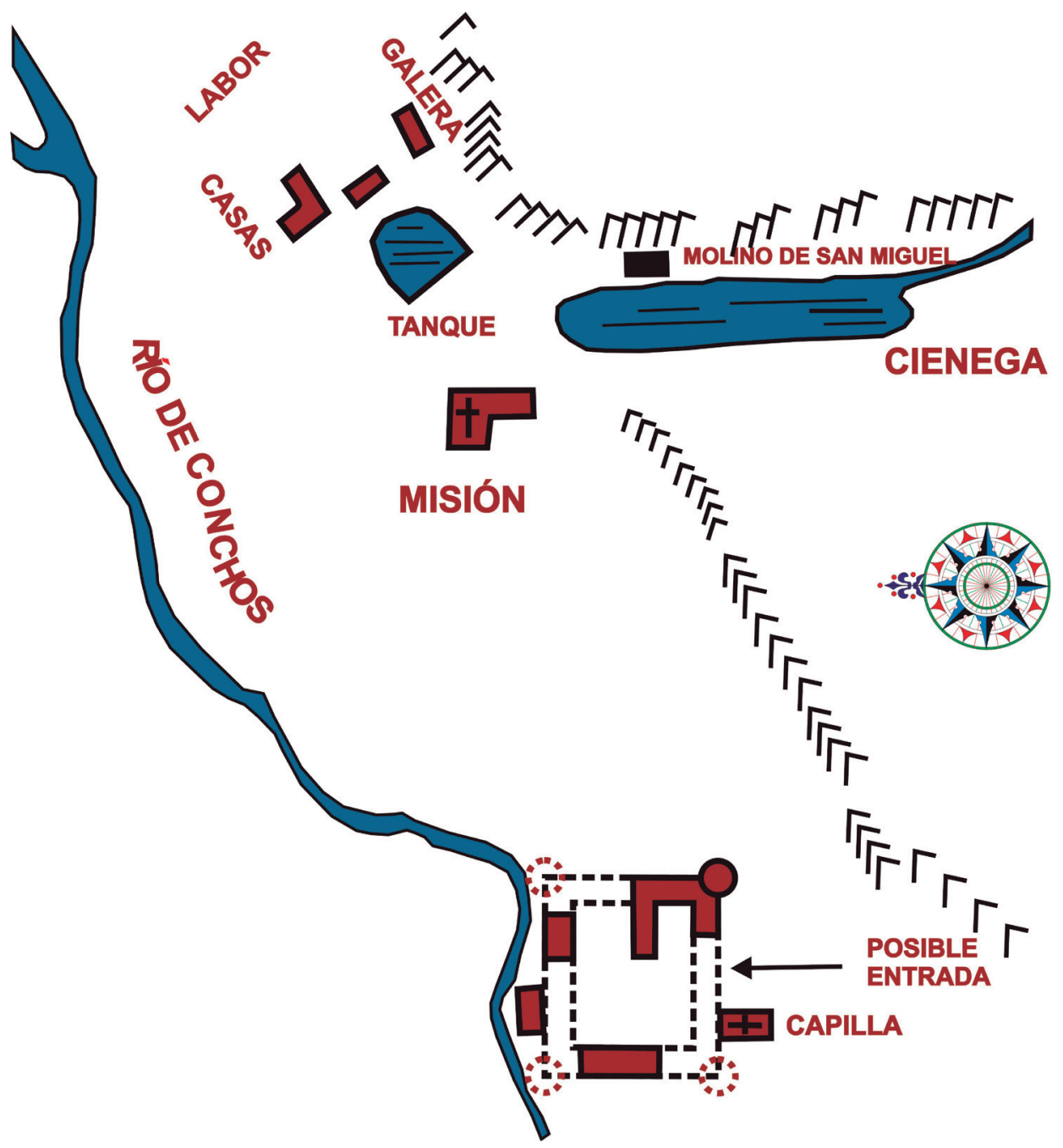

Figura 9. Presidio de Cerro Gordo, 2016. Diseño por R. Carrillo Acosta, sobre la base de Archivo Histórico Municipal de Parral [AHMP], serie Milicias y Guerra, subserie Administración de Milicias, Autos sobre la formación del Cerro Gordo por mandato del conde de Salvatierra, virrey, Pueblo del Tizonazo, 10 de agosto de 1646, caja 1, expediente $3, \mathrm{f}$. 3 vuelta y 12 vuelta.

Figura 10. Presidio de Conchos, 2016. Diseño por R. Carrillo Acosta, sobre la base de Presidio y población indígena en la Nueva Vizcaya. Siglos XVII y XVIII (p. 140), por A. Guevara Sánchez, 2011, Michoacán, México: Universidad Michoacana de San Nicolás de Hidalgo. 
devenir Vol. 4, N8, JULIO-DICIEMBRE 2017, PP. 97-122 - Estudios | ISSN 2312-7562 | E-ISSN 2616-4949

Figura 11. Presidio de El Carrizal, 2016. Diseño por R. Carrillo Acosta, sobre la base de Presidio y población indígena en la Nueva Vizcaya. Siglos XVII y XVIII (p. 125), por A. Guevara Sánchez, 2011, Michoacán, México: Universidad Michoacana de San Nicolás de Hidalgo.

Figura 12. Presidio de Janos, 2016. Diseño por R. Carrillo Acosta, sobre la base de El presidio (p. 10, Anexos), por M. Moorhead, 2012, Chihuahua, México: Gobierno del Estado de Chihuahua.

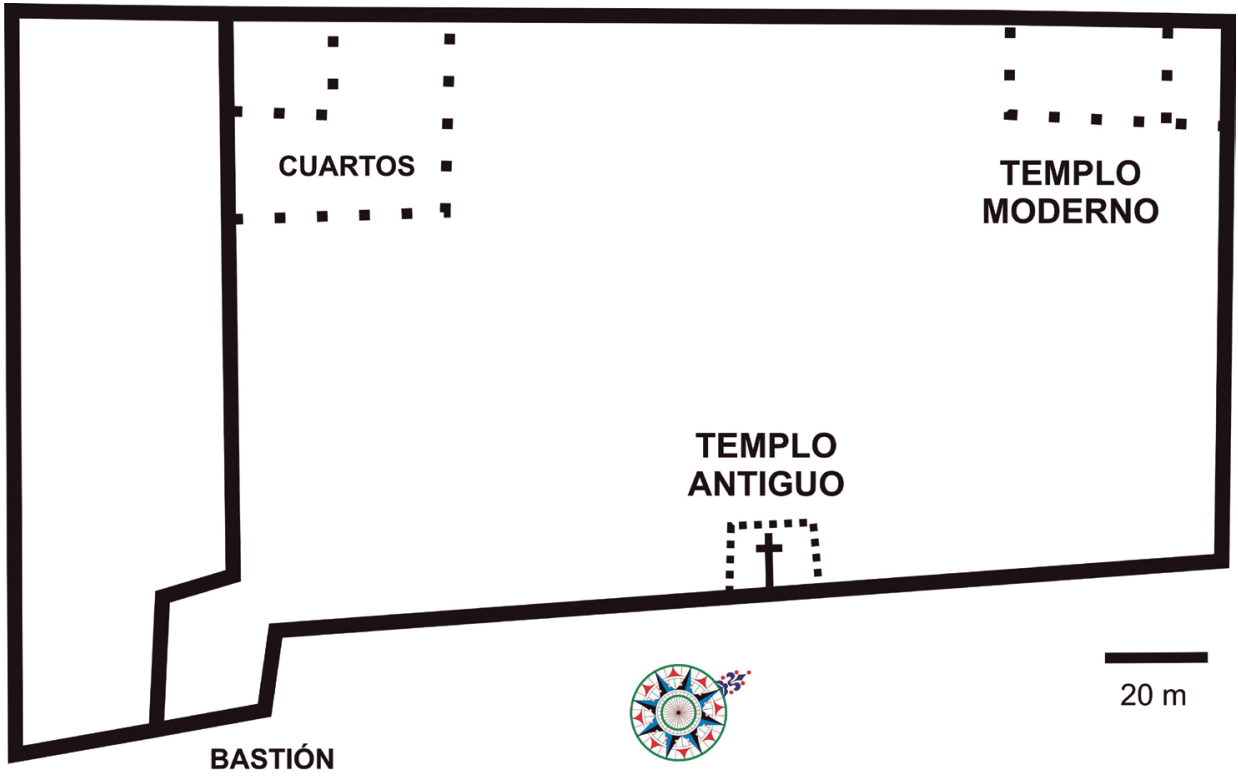

A. CASA DEL CAPITÁN Y CUERPO DE GUARDIA

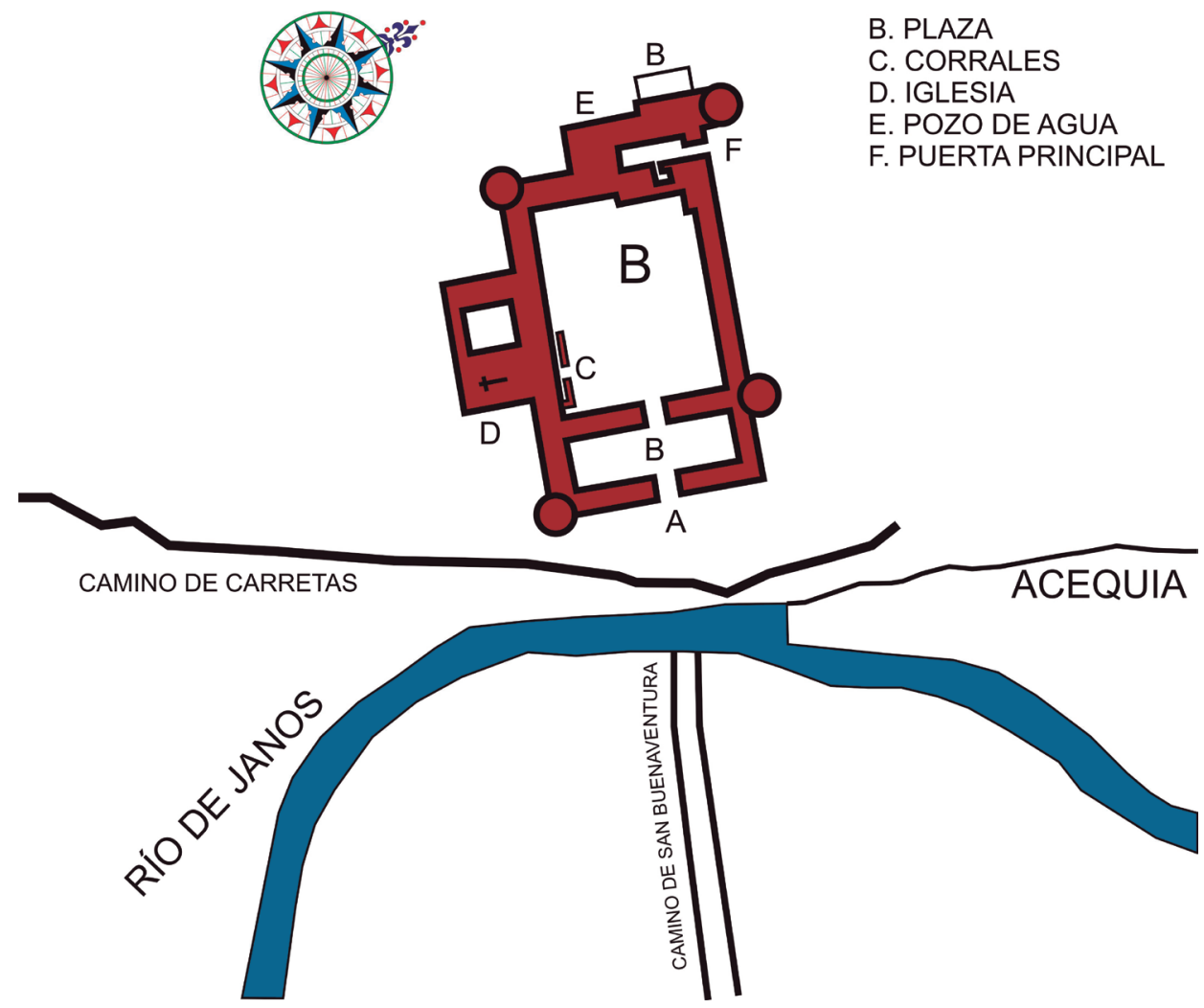




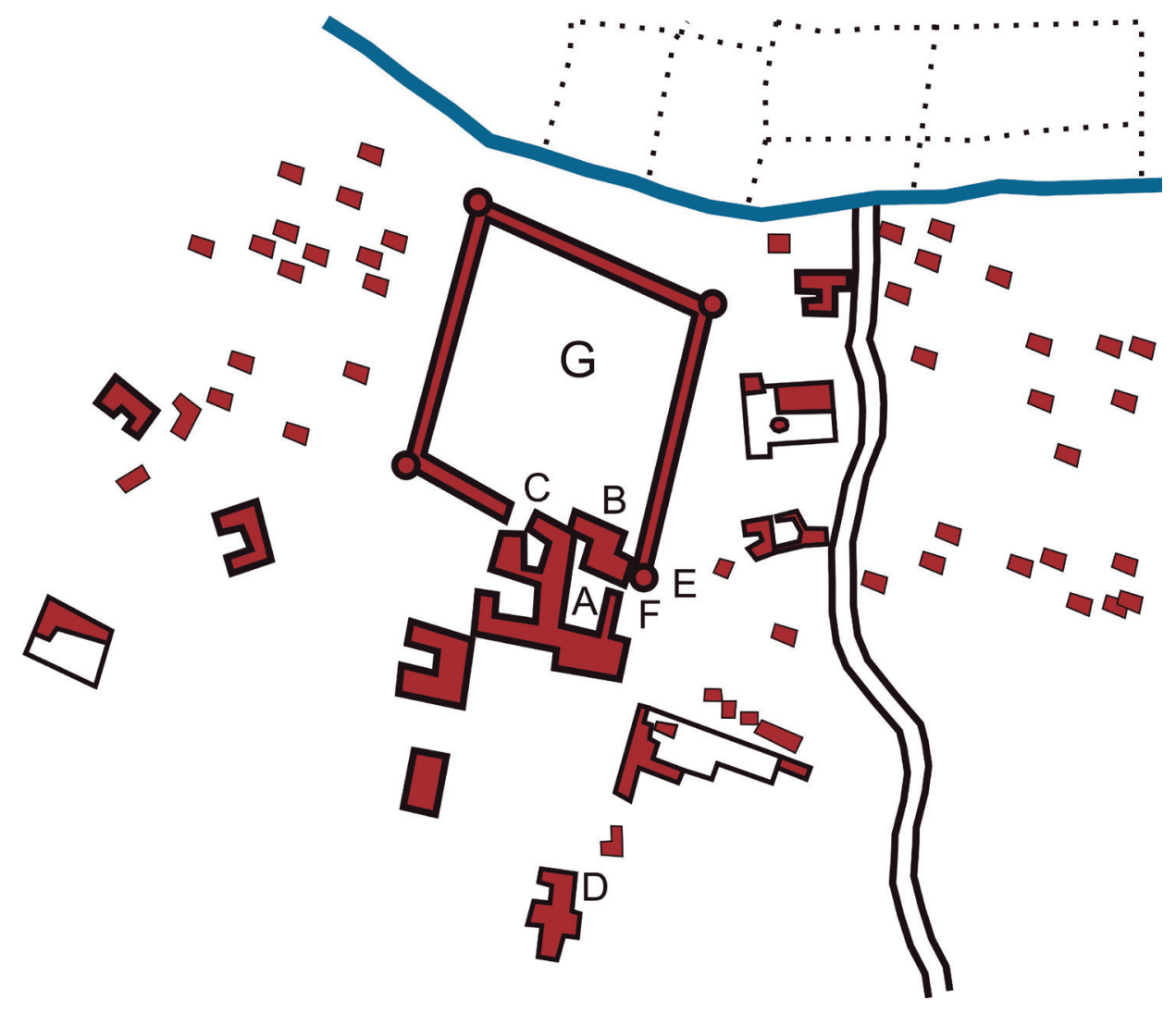

Figura 13. Presidio de Horcasitas, 2016. Diseño por R. Carrillo Acosta, sobre la base de El presidio (p. 3, Anexos), por M. Moorhead, 2012, Chihuahua, México: Gobierno del Estado de Chihuahua.
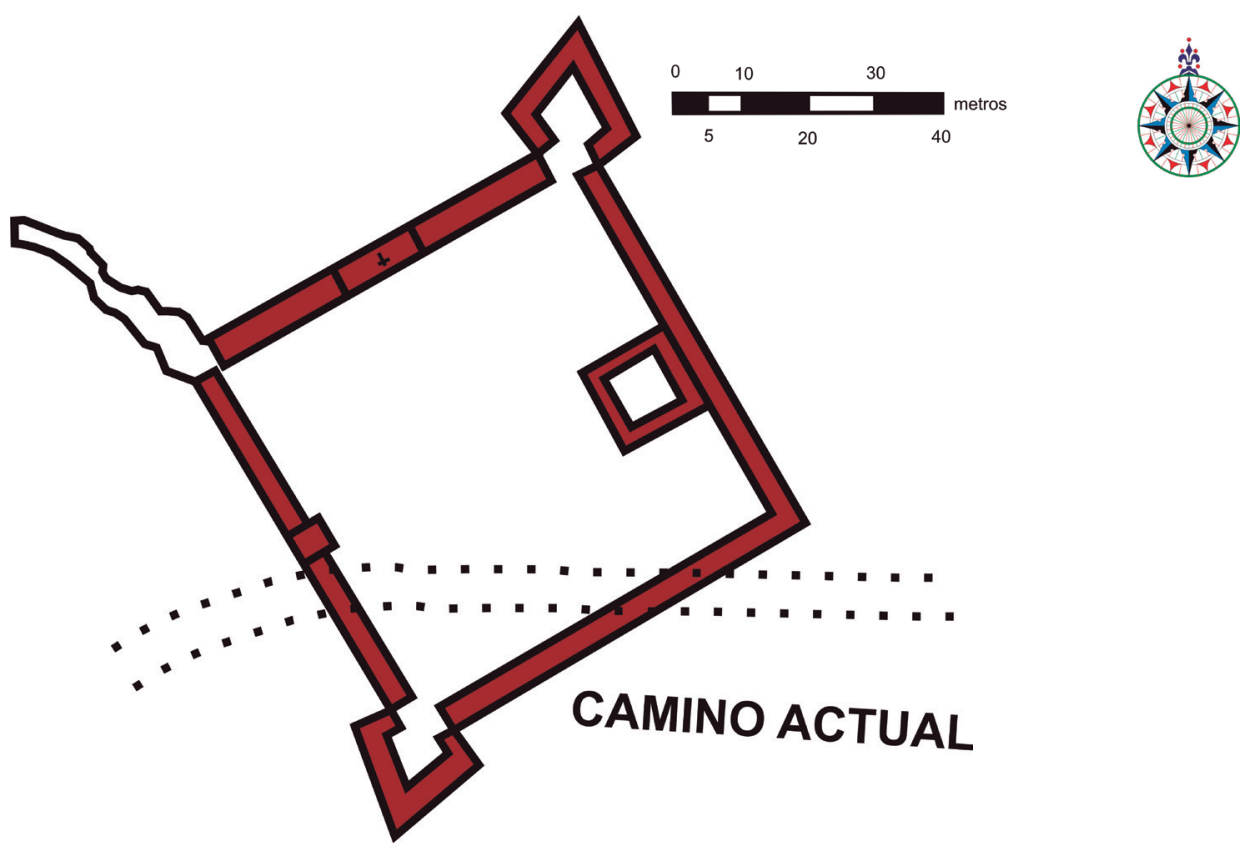

Figura 14. Presidio de San Carlos de Cerro Gordo, 2016. Diseño por R. Carrillo Acosta, sobre la base de Presidio y población indígena en la Nueva Vizcaya. Siglos XVII y XVIII (p. 148), por A. Guevara Sánchez, 2011, Michoacán, México: Universidad Michoacana de San Nicolás de Hidalgo. 
Figura 15. Presidio del Pilar, 2016. Diseño por R. Carrillo Acosta, sobre la base de El presidio (p. 15, Anexos), por M. Moorhead, 2012, Chihuahua, México: Gobierno del Estado de Chihuahua.

Figura 16. Presidio de la Bahía del Espíritu Santo. Diseño por R. Carrillo Acosta, sobre la base de Presidio y población indígena en la Nueva Vizcaya. Siglos XVII y XVIII (p. 210), por A. Guevara Sánchez, 2011, Michoacán, México: Universidad Michoacana de San Nicolás de Hidalgo.
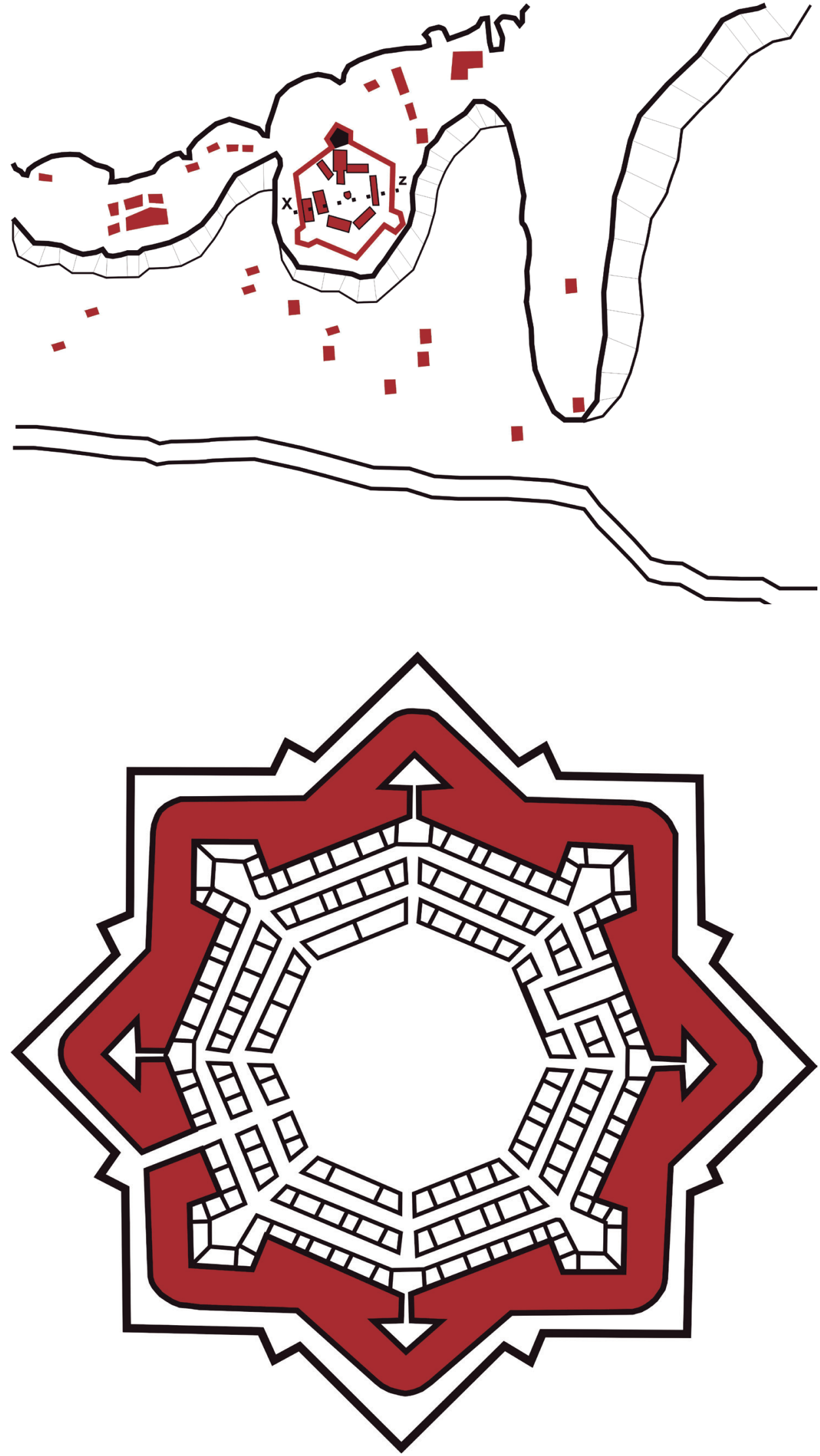



Figura 17. Presidio de El Pasaje, 2016. Diseño por R. Carrillo Acosta, sobre la base de El presidio (p. 8, Anexos), por M. Moorhead, 2012, Chihuahua, México: Gobierno del Estado de Chihuahua.
Figura 18. Presidio de Fronteras, 2016. Diseño por R. Carrillo Acosta, sobre la base de El presidio (p. 5, Anexos), por M. Moorhead, 2012, Chihuahua, México: Gobierno del Estado de Chihuahua. 


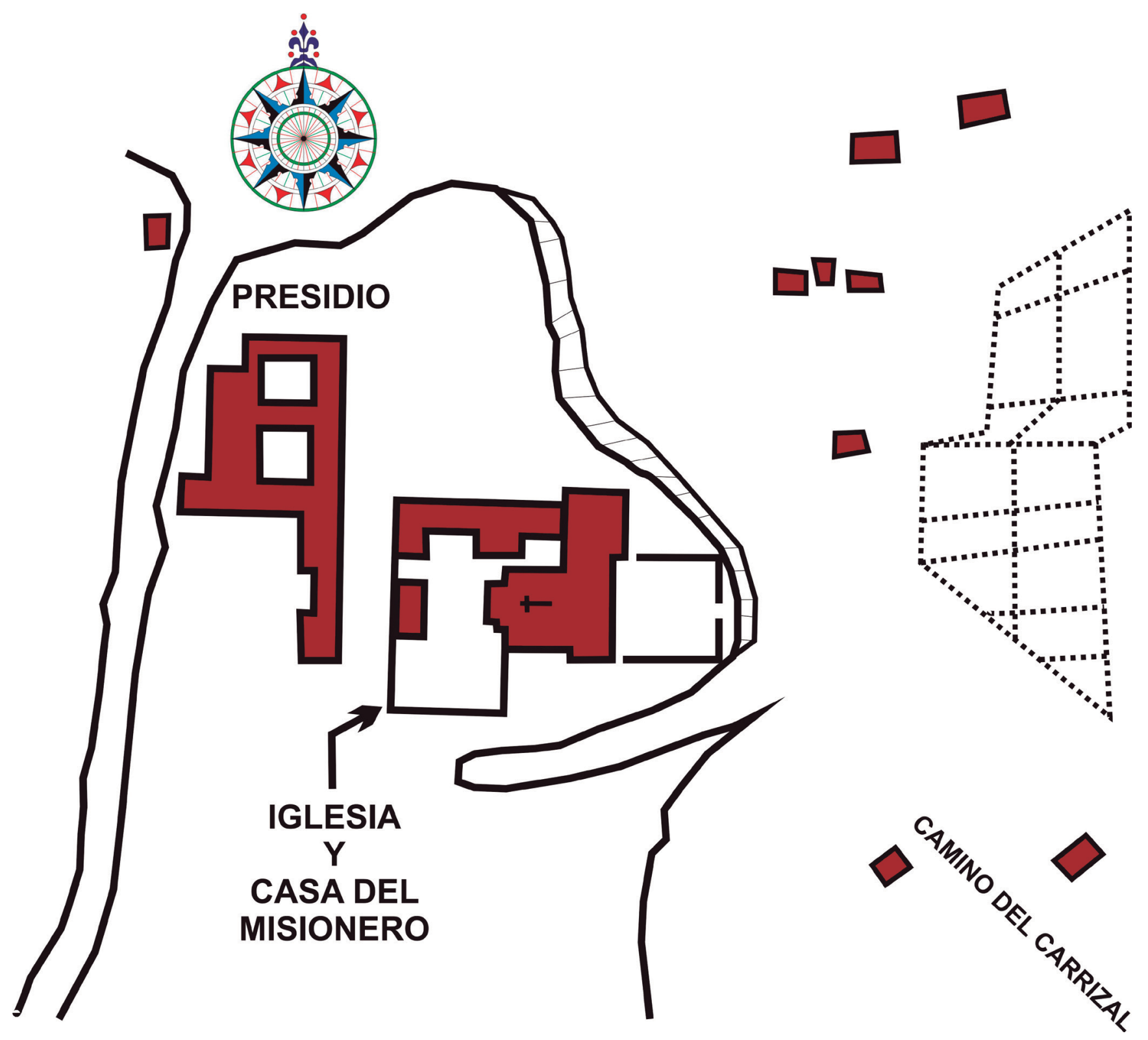

Figura 19. Presidio de El Paso, 2016. Diseño por R. Carrillo Acosta, sobre la base de El presidio (p. 18, Anexos), por M. Moorhead, 2012, Chihuahua, México: Gobierno del Estado de Chihuahua. o principal, y la otra, la más pequeña, correspondía al campanario de la capilla. En la parte posterior del mismo modelo de presidio se ubicaba la torre más grande, la cual tenía un techo plano, el cual quizá servía para colocar ahí los cañones. La entrada chica era el acceso a la capilla; detrás de esta se ubicaba un compartimiento extenso con un patio, seguramente el claustro, en cuyo extremo estaba emplazada la casa del capitán. Los compartimientos que hacían esquina con la torre más grande formaban las barracas de los soldados. En el espacio detrás de la puerta principal se localizaba la cárcel militar. (Moorhead, 2012, pp. 115-116).

En el alzado del mismo presidio (ver Figura 7), es posible distinguir la distribución de sus espacios. Los torreones sobresalen de la muralla o muros; en uno de ellos está el almacén y en el otro el campanario del templo. A la derecha se observa, marcado con líneas punteadas, lo que quizá era la acequia que conducía el agua hasta el pozo. 
Además de los elementos y espacios ya señalados, que son los componentes básicos de los presidios, tales como la casa del capitán, las habitaciones de los soldados, la capilla y los torreones, existían otros, complementarios, pero no menos importantes. Tal es el caso de las caballerizas, que en la mayoría de los presidios se solían construir en las afueras de los mismos o adosados a estos, e incluían un corral y abrevaderos. La iglesia, el almacén y los torreones se encontraban por lo regular en las esquinas. En otros diseños se integraba un espacio más, el arsenal, que se ubicaba justo al centro del presidio, quizás por un motivo práctico: que estuviese en el centro hacía más fácil tomar las armas cuando atacaban los indígenas enemigos.

Posteriormente, a los presidios en general se les integró un espacio llamado cuerpo de guardia, dedicado a la vigilancia, justo a la entrada del presidio. Soldados haciendo guardia también los había en la casa del capitán y de otros oficiales, así como en el área del arsenal. Para la vigilancia nocturna se llegaron a utilizar faroles con velas encendidas, y los soldados se comunicaban mediante gritos, empleando contraseñas. Durante la noche también se llevaban a cabo correrías (exploraciones), que requerían estar pendientes de los ciclos lunares, lo cual servía también para poder utilizar al máximo la luz del día en las correrías matutinas (Guevara Sánchez, 2011, pp. 232- 239).

Los modelos arquitectónicos y los materiales empleados, así como algunos de los elementos que componían los presidios, fueron variando con el tiempo, según las necesidades. Las dimensiones aumentaron junto con el crecimiento de las tropas, y en algunos casos el número de torreones llegó hasta seis, mientras que la altura de las murallas variaba con frecuencia. Así, el diseño arquitectónico se fue modificando: la clásica forma de cuadrado fue reemplazada por rectángulos, octágonos o diamantes, e incluso en algunos casos no se seguía una forma clara (Guevara Sánchez, 2011, pp. 232- 239).

En 1767, el militar José Ramón de Urrutia realizó 21 croquis de los presidios que visitó en el reino de Nueva Vizcaya, acompañado del ingeniero militar Nicolás de Lafora y el mariscal de campo Marqués de Rubí. La visita tenía como objetivo realizar un diagnóstico de la situación de los presidios, y el resultado, además de los croquis, fue la elaboración de reformas en los diseños y construcciones posteriores de estos presidios. Para entonces, algunos presidios ya habían pasado a ser poblaciones civiles. Para explicar con mayor detenimiento los modelos constructivos, se hará uso de algunos croquis de Urrutia, de aquellos presidios más representativos y más próximos a la región aquí estudiada.

En la información recogida durante dicha visita se puede observar el uso de cuatro modelos generales en la construcción de presidios. El primero, de tipo A, es de forma cuadrada. Entre estos destacan los presidios de El Gallo, Cerro Gordo y San Francisco de Conchos, todos presidios ubicados en el Camino Real, en la parte norte de México colonial (ver las Figuras 4, 8, 9 y 10).

\section{Utilización del espacio en los presidios}

En este apartado se describirá la distribución de espacios de los presidios en general, y más adelante se abordará de manera específica el caso de estudio, el presidio de $\mathrm{El}$ Pasaje, ya que el objetivo de este apartado es plantear el contexto.

Los presidios contaban con espacios diferenciados para el alojamiento. Por un lado, estaban las habitaciones individuales para los soldados, entre 10 o 15 cuartos, en los cuales había pocas comodidades; por ejemplo, se dormía en el suelo, sobre esteras o petates. A los soldados no se les permitía llevar a sus esposas a vivir al presidio. Aparte, se disponía de lo que llamaban chozas de los soldados, separadas del edificio, donde habitaba la familia de cada soldado. Las dimensiones de los cuartos dentro de los presidios eran de $6.5 \times 7$ metros (Moorhead, 2012, p. 120). 


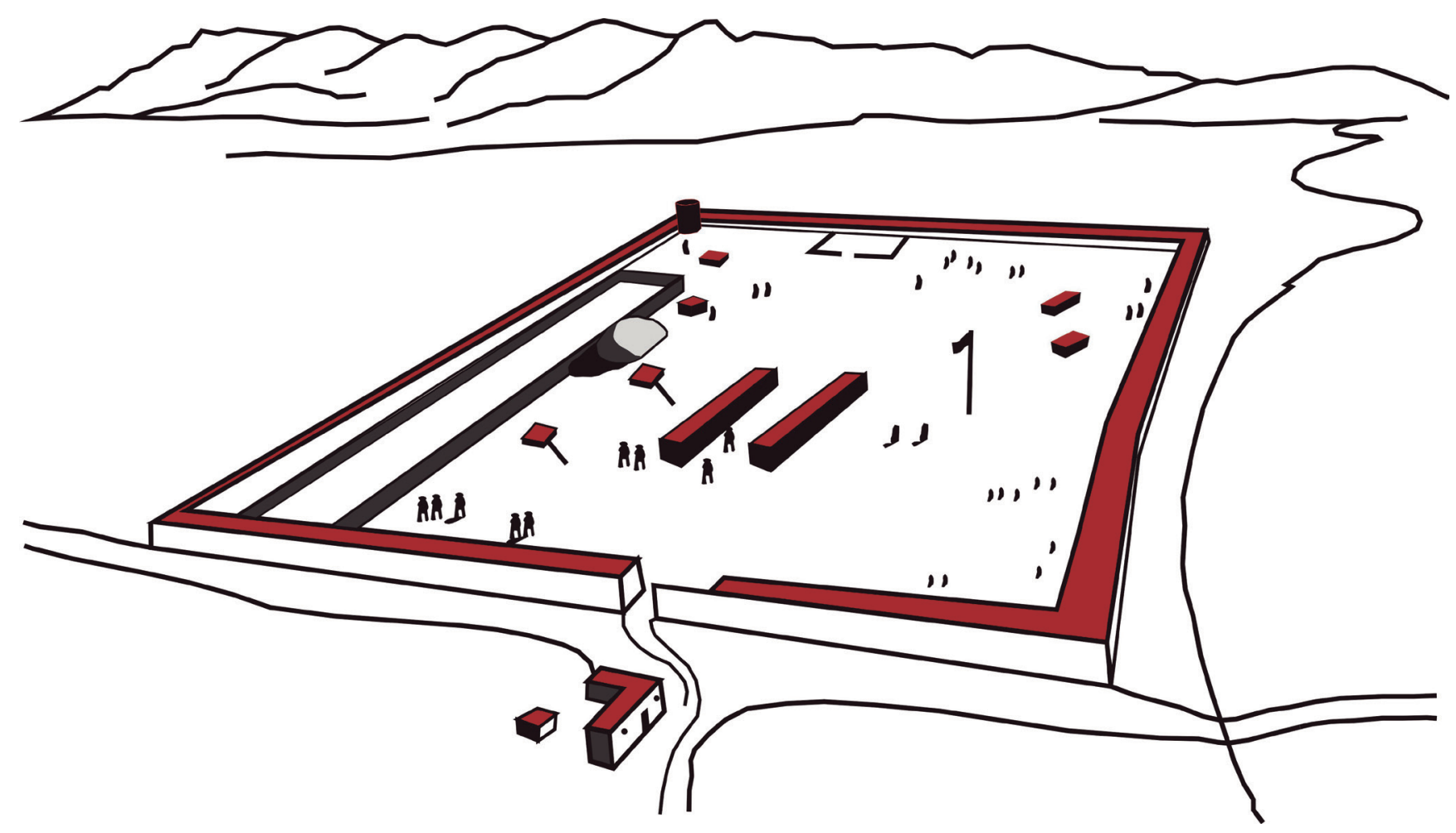

Figura 20. Presidio de Tucson. Diseño por R. Carrillo Acosta, de sobre la base de El presidio en México en el siglo XVI (p. 131), por L. Arnal, 1998, D. F., México: Universidad Nacional Autónoma de México.
Asimismo, había otras habitaciones, dedicadas a los capitanes, que tenían espacios separados y privados. Además, contaban con cuartos para los sirvientes que, por lo general, eran indígenas jóvenes capturados, cuya tarea era cargar las armas, mantener la ropa limpia, cuidar los caballos y acompañar al soldado en las campañas. Si el presidio era chico, debían dormir afuera o en el patio (Arnal, 1998, p. 210).

También había espacios, tal vez improvisados, destinados al descanso de los pasajeros que transitaban los caminos, particularmente los del norte. Es importante señalar que tanto poblaciones, mesones y presidios debían estar establecidos a 40 leguas de distancia entre sí, aproximadamente; usualmente, la distancia oscilaba alrededor de los 180 kilómetros, según el marqués de Rubí (Pucci, 1993, p. 162). En el caso del norte, estas distancias se incrementaban; por ello el viajero alternaba alojamiento y protección en haciendas, parajes naturales, mesones (donde los había) y presidios.

Hay poca información disponible sobre este servicio, ya que por lo regular era ofrecido de manera gratuita. Quizás, en las haciendas o mesones se encontraban mayores comodidades, pues contaban con camas, colchones, mesas y sillas, incluso ventanas. No obstante, en los espacios de asistencia de los presidios había un elemento que no estaba presente en otros: la seguridad. Las construcciones sólidas y la presencia constante de soldados brindaban un ambiente de tranquilidad al viajero.

A pesar de que resulta poco probable que hubiese cuartos para huéspedes en todos los presidios, sí se cuidaba que hubiera un espacio para los oficiales reales, el cual les servía como espacio de descanso en sus jornadas hacia los distintos y lejanos pueblos del norte. Además, les servía para instalar ahí una aduana, bajo el nombre de Casa Real. Allí se revisaban las mercancías, y se hacía una lista pormenorizada de los arrieros y lo que transportaban; muchos de ellos incluso se alojaban en el mismo presidio. Dichas casas reales llevaban el nombre de cada presidio, pero como aduana, por ejemplo, aduana de El Pasaje. 


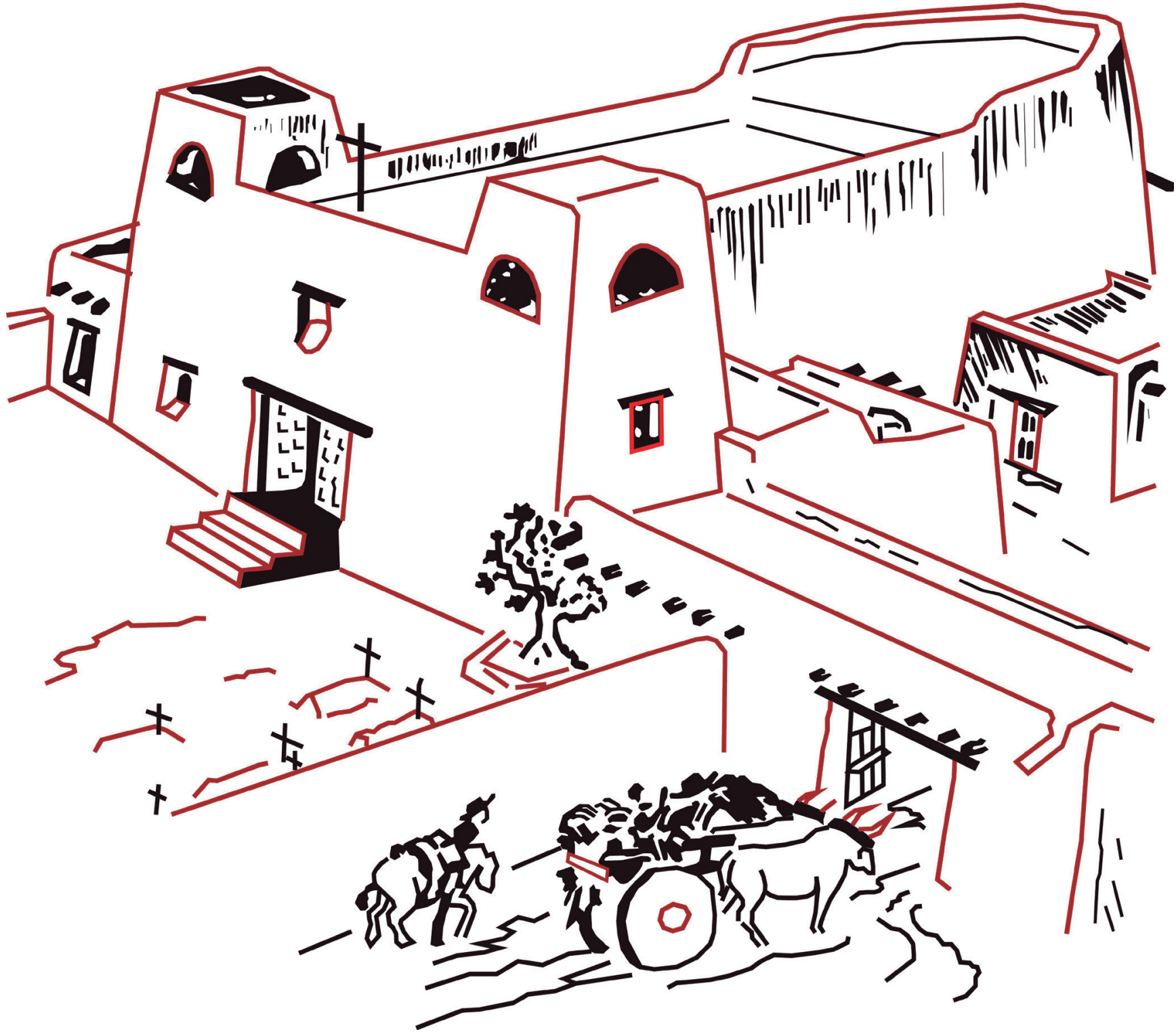

Era importante que en los presidios se contara con un espacio para el resguardo de los caballos y los diferentes animales de los que hacían uso los soldados, conocidos como caballerizas o corrales. De acuerdo al número de soldados que se dejaba en cada presidio, un promedio de 30 a 50, se les destinaba una cantidad de caballos (cuatro, cinco y hasta diez para cada soldado), los cuales deberían estar equipados con sillas, riendas y brocados. Los soldados los empleaban para trasladarse, pero además les permitían llevar consigo otros elementos de uso necesario en sus empresas contra los indígenas enemigos, tales como armas, casco, escudo, ropa, alimento, etc. Estos caballos los debían cuidar, pues eran muy codiciados por los indígenas hostiles. Cuando era pequeño el presidio, las caballerizas se construían afuera, y se levantaban tapias de piedra. Debido a la frecuencia de los robos de estos animales, el marqués de Rubí llegó a señalar la necesidad de levantar muros alrededor de ellas (Guevara Sánchez, 2011, p. 232).

En el mismo presidio se resguardaban animales de tiro como las mulas, las cuales eran empleadas para transportar armamento, alimentos o leña. De la misma forma,
Figura 21. Capilla de presidio. Diseño por R. Carrillo Acosta, sobre la base de Los Atapascanos en Nueva Vizcaya, (p. 73), por A. Guevara Sánchez, 1989, Distrito Federal, México, Instituto $\mathrm{Na}$ cional de Antropología e Historia. 
devenir Vol. 4, N8, JULIO - DICIEMBRE 2017, PP. 97-122 - EstudIOS | ISSN 2312-7562 | E-ISSN 2616-4949

UNIVERSIDAD NACIONAL DE INGENIERÍA, LIMA

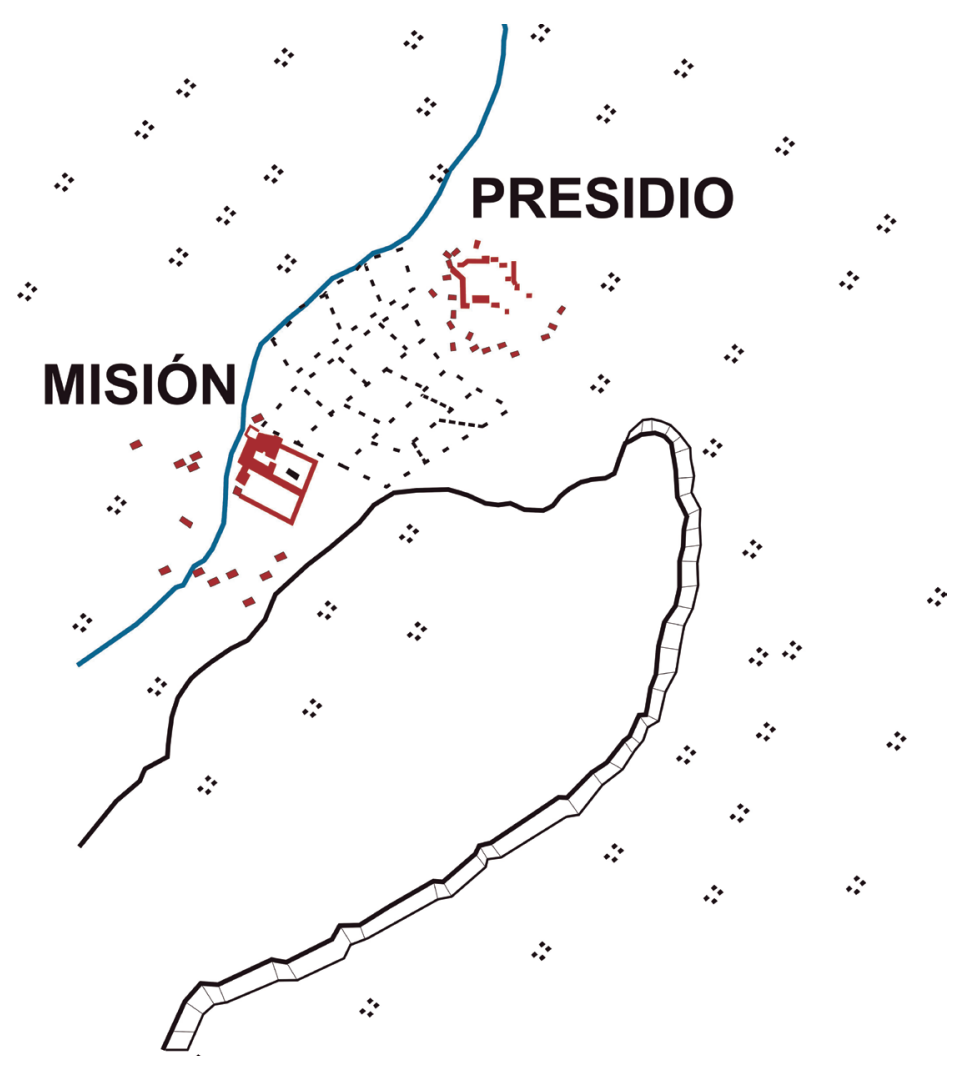

Figura 22. Presidio - misión de San Francisco Javier de Valero. Diseño por R. Carrillo Acosta, sobre la base de El presidio (p. 1, Anexos), por M. Moorhead, 2012, Chihuahua, México: Gobierno del Estado de Chihuahua. se contaba allí con una considerable cantidad de ganado lanar o vacuno, el cual era destinado especialmente a la elaboración de alimentos para los soldados, y también podía ser utilizado como medio de intercambio con los indígenas para conseguir variedad de alimentos, diferentes a los que allí se cosechaba. La necesidad de contar en cualquier momento con estos medios de carga y transporte hacía necesario que también se practicara la cría de ganado; es decir, el soldado debía tener conocimientos de ganadería o encargar a algunos indígenas que se dedicaran a esta actividad complementaria (Arnal, 1998, p. 211).

La disposición de que cada soldado de presidio contara con diez caballos no se ajustaba muchas veces a la realidad; en muchos casos no se cumplía, y en muchas ocasiones los soldados no eran bien aprovisionados con caballos, comida ni vestimenta.

El patio central del presidio, conocido como patio de armas, tenía múltiples funciones y usos. Servía como lugar de reunión de la población y los soldados, y en otras ocasiones también se concentraba ahí al ganado. Su función más inmediata era la de ser plaza de armas; es decir, allí se pasaba revista, se hacían maniobras y formaciones de tropa. Se utilizaba también como un espacio social o comercial, donde se distribuían los alimentos, se hacían fiestas, y se realizaban actividades de enseñanza y entretenimiento. También se llevaban a cabo eventos ceremoniales como misas, avisos y castigos (Arnal, 1998, p. 212).

Una actividad alternativa era la enseñanza de los sistemas de cultivo, cosecha y siembra, la cual se realizaba afuera del presidio. A los indígenas se les instruía para que aprendieran a coser y tejer sus ropas, a cocinar, a construir sus casas de adobe y madera, así como a elaborar sus utensilios de comida a base de cerámica. También se les inculcaba el aseo personal. No todas las actividades se llevaban a cabo dentro del presidio: al- 


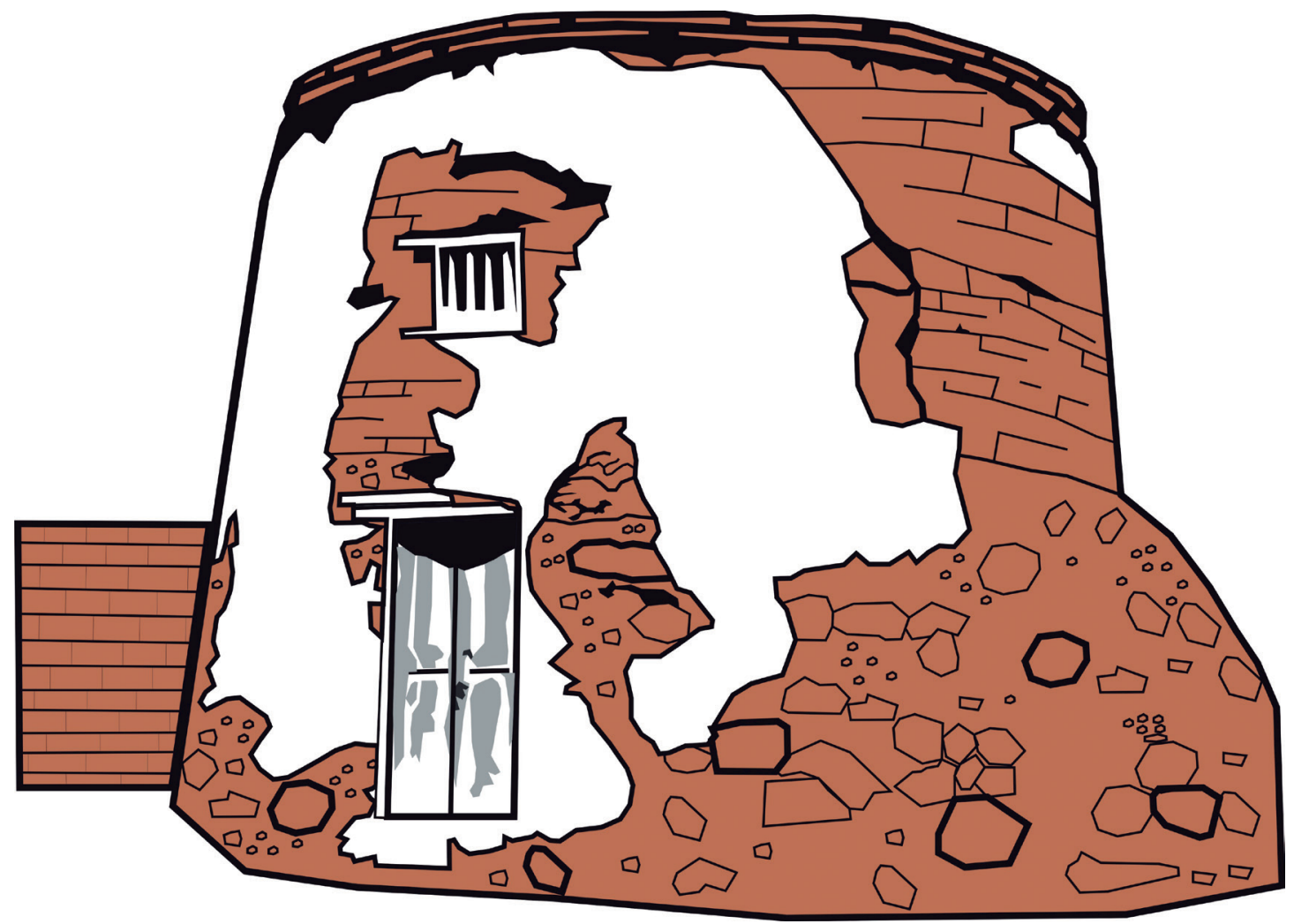

gunas se realizaban en los alrededores. Era indispensable promover que los indígenas fueran autosuficientes y que elaboraran sus propios productos, por lo cual en algunos presidios se construyeron molinos de tracción animal o de fuerza hidráulica, con los que se obtenía nixtamal o harina para preparar tortillas y pan (Arnal, 1998, pp. 219-220).

En los presidios había varias dependencias de apoyo a la población y a los soldados, que bien se podrían considerar complementarias, tales como la herrería y carpintería, actividades necesarias para la fabricación de herramientas. Ahí se fabricaban ruedas para las carretas, y también se reparaban las armas y arreos de montura. Otros servicios se brindaban en las armerías y el polvorín. Estos espacios solían ser cuartos cerrados sin ventanas, muchas veces instalados fuera del presidio, como en el caso del presidio de Tucson (Arnal, 1998, p. 211).

En la Figura 20 se aprecia lo despoblado y desolado del lugar, así como la ausencia de fuentes de agua, salvo lo que parece ser una acequia o arroyo al costado del presidio, aunque no se señala el discurrir del agua. Cuando se establecía un presidio, era de vital importancia cuidar que se hiciera en las cercanías de algún afluente de agua; ríos o manantiales eran más que idóneos. El agua era indispensable, sobre todo para el ganado y para la construcción. En algunos casos se hicieron pozos y cisternas para captar el agua de la lluvia (Arnal, 1998, p. 219).

En cuanto al presidio específicamente, este consiste en una estructura rectangular, con una gran plaza central alrededor de la cual están distribuidas todas las habitaciones. Al frente se encuentra la única entrada, y el camino por donde se aproximan un arriero y su recua de mulas. Afuera del presidio, se encuentra lo que tal vez es la garita o aduana, y en el interior, al fondo, es visible un torreón. No se pueden distinguir las dependencias, pero sin duda contaba con aquellas consideradas básicas. En el centro se aprecia una bandera
Figura 23. Torreón. Diseño por R. Carrillo Acosta, sobre la base de Los atapascanos en Nueva Vizcaya (p. 69), por A. Guevara Sánchez, 1989, Distrito Federal, México: Instituto Nacional de Antropología e Historia. 
y otros cuartos, donde tal vez realizaban actividades comerciales los arrieros; es decir, allí se ubicaba el mercado. Se aconsejaba que en los presidios se contara con terrenos adjuntos donde los soldados pudieran ejercitarse y tener su preparación.

Además, en muchos presidios había un espacio destinado para una capilla, la cual por lo general era pequeña. Según Luis Arnal, se estipulaba que esta debía estar ubicada fuera del recinto del presidio, para que los indígenas de las misiones o pueblos cercanos no relacionaran la milicia con el dios católico. Por otro lado, se consideraba que su presencia era indispensable, pues se pretendía formar buenos soldados y buenos vecinos. En la mayoría de los presidios había poblados y capillas, pero existe gran variación en cuanto a su ubicación (1998, pp. 212-214).

Al espacio de la capilla también se integraba el panteón. Capilla y panteón debían permanecer relativamente independientes del presidio, por lo cual poseían su propio espacio. En la Figura 21 se aprecia perfectamente cómo había en la entrada un muro que separaba estos espacios.

Era muy importante que los militares y los misioneros viajaran juntos para apaciguar, evangelizar y dominar a los indígenas, y a la vez ocupar su territorio; por ello, era común encontrar capillas junto a los presidios, o misiones cercanas a ellos, tal y como se aprecia en la Figura 22. La idea era que la religión estuviera siempre con los soldados y los indígenas.

Otro elemento presente en los presidios era el bastión o reducto, el cuarto más resistente de todos, ubicado en una de las esquinas o al centro del presidio, a la manera de la torre de homenaje en los castillos europeos. En esta se refugiaban las mujeres y niños, así como a los indios pacificados, cuando era atacado el presidio y corría riesgo de ser tomado. Se trata de una fortificación con troneras y una sola puerta recia de madera. Cuando se pacificaba la región, pasaba a ser utilizada como almacén o capilla (Arnal, 1998, p. 214-215). Por otro lado, su sola presencia y altura provocaba temor en los indígenas enemigos, a tal grado que incluso se llegó a proponer que en las casas particulares se construyeran torres (Guevara Sánchez, 2011, pp. 233-235).

En el caso de las torres, torreones o cubos, como también se les conocía, su función principal era la vigilancia (ver Figura 23). La torre era un elemento de refuerzo sobre todo en las esquinas, ya fuese una o varias, y además podían fungir como campanarios (Arnal, 1998, p. 216). Los torreones debían ser más altos que los muros, y en sus azoteas había dinteles altos que servían de parapetos.

En los presidios también había almacenes para guardar alimentos y ropa, los cuales eran destinados a los indígenas. También se resguardaban allí los materiales de construcción, como vigas, adobes, clavos, tejas, añil y otros; incluso se guardaban implementos de labranza y semillas. Los almaceneros llevaban el control de las entradas y salidas. El capitán o teniente de capitán hacía los repartos en presencia de un fraile, que firmaba como testigo (Arnal, 1998, p. 218).

Con el paso del tiempo, el adobe, en muchos presidios y otras construcciones, se fue remplazando por el ladrillo. Tal fue el caso del presidio que se ubicaba en GuajoquiIla: según los documentos revisados del Archivo Histórico Municipal del Parral, en los gastos de su fábrica se indica la utilización, en 1784, de 4,500 ladrillos destinados a la construcción de los pisos y las trojes de la pieza donde se acopiaban los bastimentos para la tropa (AHMP, 1784).

\section{Transformación de las fortificaciones y el paisaje}

El trabajo de la tierra, el cercado de sus propiedades y la cría de ganado eran actividades transformaban paulatinamente el paisaje urbano, además de la construcción 
de las murallas del presidio, la capilla y las casas de los soldados, indígenas y demás pobladores de las cercanías. Se utilizaban como materiales de construcción piedra de la región, que se tomó de las peñas; tierra, para el terrado de los techos; y madera para los establos. Un cambio evidente era el del trazado de caminos: con las pisadas de caballos, bueyes y mulas, además de las carretas cargadas de metal o mercaderías, así como de pasajeros, se fue dando forma a estas rutas y caminos entre poblados y presidios, que implicaron la progresiva apropiación y dominio de la región.

Los indígenas fueron prácticamente arrancados de las peñas para ser asentados en congregaciones de misiones o en pueblos de indios, donde algunos fueron condenados a ser esclavos de los españoles. En cada población se establecían casas de vecinos, con espacios amplios de terracería, a manera de calles. Por otro lado, fueron llevados a los presidios, cuyas plazas debían ser áreas sociales, educativas y de comercio, donde la figura del capitán era determinante: él distribuía o mandaba a distribuir armamento, vestimenta, alimentos y salario; disponía las actividades de trabajo; y se encargaba de la impartición de justicia. Además, asociado con los gobernadores y dueños de haciendas, imponía las reglas y el rumbo de la vida en el presidio y, por qué no, del septentrión (norte), incluso mucho después incluso de que dejaba de ser fortificación militar, pues pasaba de ser capitán a alcalde y sus soldados se transformaban en vecinos.

La transformación del paisaje se hizo evidente cuando las fortificaciones dejaron de funcionar como puestos militares y se adaptaron para operar como poblaciones civiles, casas o vecindades. Entonces se redistribuían las tierras de campo, de labor o ganaderas, así como los espacios arquitectónicos para que se adaptaran a las nuevas necesidades. Algunos fuertes, cuando dejaron de operar, no se convirtieron en poblaciones, sobre todo los que no estaban en la vera principal del Camino Real: su vida y permanencia fue efímera, y se trasladó su guarnición de soldados, en la mayoría de los casos, a otros puestos militares.

\section{Presidio de Nuestra Señora de la Purísima Concepción de El Pasaje}

La historia de este fuerte comienza entre 1569 y 1600, al recibir Pedro de Morcillo ciertas mercedes de tierras, de las cuales tomó posesión y comenzó a hacer vida; tiempo después adquirió su propiedad Pedro de Cosío y la nombró Estancia de San José. En 1690 Juan B. Escorza fue comprando los derechos a sus herederos y fundó otra estancia con el nombre de Estancia del Álamo; poco antes, en 1685, se dispuso la instalación del presidio, llamado Purísima Limpia Concepción de la Señora Virgen María del Pasaje, cuyo capitán era el mismo Escorza. Cabe destacar que el presidio no ocupó todo el espacio de la estancia, y que varias personas hacían uso de las tierras y aguas de la estancia, incluso después de creado el presidio (Favela González, 2003, p. 127).

A la muerte del capitán, sus bienes y ambas estancias fueron rematados en 1702, cuando probablemente las adquirió Pedro Sánchez Tagle, pues tenía terrenos en sus cercanías. En 1703 se nombró capitán del presidio a Martín de Alday, quien inmediatamente se dispuso a combatir a los sublevados del Bolsón de Mapimí, contra los apaches y cocoyomes. También tuvo el cuidado de asentar indígenas pacificados babosorigames y tarahumaras, y fundó así el pueblo indígena de Cinco Señores.

En dicho presidio se estableció muy pronto una cofradía, la de la Purísima Concepción, la cual fue reconocida en 1723 por el mismo obispo de la Nueva Vizcaya. En 1751, por disposición real, se decretó que quedaran extintos los presidios en dicha región, incluidos $\mathrm{El}$ Pasaje, El Gallo, Cerro Gordo y Conchos; no obstante, el de El Pasaje continuó su labor, pues permaneció como estancia y poblamiento civil, como estipulaba el decreto de su creación.

Más tarde, en 1765, otro obispo, Pedro Tamarón y Romeral, en su visita pastoral, llegó al presidio e hizo la siguiente descripción: 
La dotación de este presidio es de treinta y cinco soldados que paga la casa del conde del Álamo, su situación la tiene en su camino real que va de Durango y México hasta Chihuahua, es paraje muy preciso este presidio para escoltar en este camino las conductas de oro y plata que pasan todos los años, para contener si hubiere algún movimiento de los indios de la Tepehuana y ocurrir a las fronteras de Cuencamé y defender los términos de Parras, su laguna y dilatada ensenada que por varias partes ha sido y es invadida de indios enemigos, y no ha quedado otro recurso ni defensa desde que el año de mil setecientos cincuenta y uno se quitaron los presidios cercanos... treinta y tres leguas, la gente que en el reside son ochenta y tres familias, con quinientas nueve personas. (citado en Favela, 2003, p. 49)

El traslado de los presidios del Camino Real obedecía a que ya se consideraba pacificada la región, además de que se estaba corrompiendo su función, pues eran utilizados sus soldados para el servicio personal de los capitanes en sus haciendas; y sus caballos se observaban como un verdadero negocio en el mismo septentrión. Así pues, sus tropas se trasladaron hacía el norte, a nuevos presidios. El presidio de Santa María de Cerro Gordo conservó parte de su nombre, al denominase entonces San Carlos de Cerro Gordo; los de El Gallo y Conchos cambiaron de nombre; aunque no se ha identificado con exactitud su ubicación en la línea de presidios que se formó con ellos, al lado de otros 48 más, se advierte que el grueso de la guarnición se trasladó y parte de los soldados se quedaron a fundar los que más adelante serían, hasta la actualidad, los ayuntamientos de San Pedro de El Gallo y San Francisco de Conchos. Se observa pues, que el de El Pasaje era el único que permanecía con funciones militares y civiles al mismo tiempo (Carrillo, 2013) (ver Figura 4).

Un año después, en 1766, Nicolás de Lafora realizó una visita a los presidios del septentrión, cuando dio cuenta del abandono de las construcciones de lo que fueron los presidios de Cerro Gordo, El Gallo y Conchos, y señaló que se insinuaban modificaciones en los espacios de las mismas para ser adaptados como viviendas de familias. Probablemente, la transformación de los presidios en poblaciones tomó tiempo, pues ya más adelante, específicamente a principios del siglo XIX, se observaron elecciones para nombrar alcaldes en dichos espacios (De Lafora, 1939). Durante dicha visita, De Lafora iba acompañado por el Marqués de Rubí, con la intención de realizar un reconocimiento y diagnóstico del funcionamiento de los presidios y de las poblaciones derivadas de ellos. El producto de ello fue la elaboración de una serie de croquis de los presidios del septentrión, de reformas en el reglamento general de operaciones de los mismos y la conformación de una línea de presidios en la frontera, la cual se encontraba en Chihuahua (ver Figura 5).

Cuatro años después, en 1770, cuando la función militar del fuerte era ya obsoleta, se ordenó que los soldados que lo ocupaban fueran expulsados, sus casas derribadas y sus tierras expropiadas. Sin embargo, con el tiempo, sus hijos regresarían a poblar ese mismo sitio; además, tras su expulsión, el resto de la población permaneció habitando el lugar. En 1777 se realizó una nueva visita, esta vez liderada por Fray Agustín de Morfi y el comandante Teodoro de Croix, pues había noticias de nuevas rebeliones, las cuales habían ocasionado que los ranchos que se habían formado en torno a la ahora Hacienda del Pasaje se despoblaran. En el relato de Morfi se señalaba que

Es hermosa esta hacienda y de una situación comodísima, en un gran llano circundado de sierras, con buenas aguas, suficientes al sustento y riego de una numerosa poblazón [población]. Por el despueble de los ranchos inmediatos, se juntaron aquí hasta 35 familias. La casa es nueva, con buenas luces y no mal distribuida; la capilla capaz y decente; por junto a ella corre un copioso arroyo, de donde beben los vecinos. Entre estos edificios y las abatidas chozas de los antiguos soldados, se hace una plaza cuadrada en la que se puede formar gran número de tropa. (Favela González, 2003, p. 51)

Así permaneció esta hacienda; poco tiempo después de esa visita, regresarían los hijos de los soldados a tomar posesión, a retomar el legado de sus padres y las órdenes expresas en el establecimiento del presidio, que indicaban que los soldados y sus des- 
cendientes debían convertirse finalmente en los pobladores del sitio. No tuvo la misma suerte el sitio aledaño, conocido como la hacienda de Santa Catalina del Álamo, ya que después del movimiento de independencia de México se despobló.

En adelante, El Pasaje atravesó despoblamientos, ataques de apaches, guerras contra los franceses -en el siglo XIX- y reformas agrarias -en el siglo XX-, pero ya esa es otra historia. En la actualidad, El Pasaje subsiste, poblado por los descendientes de los soldados, mas no así el edificio del presidio. Solo permanecen evidencias de las construcciones originales, como cimientos o parcialidades de muros, a partir de las cuales se puede todavía explorar su historia y arqueología para explicar los procesos que atravesó hasta convertirse en el actual ayuntamiento. Sin duda hay otras historias de presidios en todo el septentrión, específicamente en la vera principal y los ramales del Camino Real de Tierra Adentro.

\section{Conclusiones}

Esta investigación es el comienzo de una labor más exhaustiva, que se está llevando a cabo de forma colectiva para lograr el rescate y la difusión del patrimonio por parte del Grupo de Investigación Historia e Interpretación del Patrimonio. ${ }^{11}$ El proyecto pretende, en principio, hacer un diagnóstico del patrimonio cultural y natural de México, para lo cual es necesario realizar la identificación del mismo. La línea de investigación abarca el Camino Real de Tierra Adentro, las políticas públicas de conservación del patrimonio, el arte, la vida cotidiana, el patrimonio industrial, las festividades y las tradiciones, entre otras temáticas.

Con esta investigación se ha logrado identificar las fortificaciones en el septentrión, específicamente en el tendido de la ruta histórica del Camino Real de Tierra Adentro. Asimismo, se ha dado cuenta de la historia de la conformación de algunas fortificaciones, y de sus habitantes, soldados, frailes, autoridades civiles y comunidades indígenas, entre otros. Ello ha permitido un acercamiento a las problemáticas que se presentaban en torno a un sistema defensivo, pero también de ocupación del espacio septentrional. La investigación, además, ha permitido detectar que es necesaria una investigación multidisciplinar, pues la mayoría de las fortificaciones identificadas se encuentran en estado de abandono, ya no existen o se han modificado demasiado en pos de transformarlas en poblaciones civiles. Así, resulta necesario el aporte de diversos especialistas para reforzar los objetivos del proyecto. Arqueólogos y arquitectos, sobre todo, con su trabajo aportarán información relevante para complementar la historia de cada fortificación, mediante levantamientos arquitectónicos, planos y mapas cartográficos.

Gracias al presente estudio también se ha logrado verificar que hay avances en la reconstrucción de algunas fortificaciones, no solo de carácter histórico, sino que implican recrear, restaurar e, incluso, con la potencialidad patrimonial, su conversión en museos in situ, que permitan o fomenten el desarrollo integral, socioeconómico y cultural de las comunidades donde se encuentran.

\section{Referencias}

Arnal, L. (1998). El presidio en México en el siglo XVI. D. F., México: Universidad Nacional Autónoma de México.

Arnal, L. (2006, 1 de agosto). El sistema presidial en el septentrión novohispano, evolución y estrategias de poblamiento. Scripta Nova [revista electrónica de Geografía y Ciencias Sociales]. Recuperado de http://www.ub.edu/geocrit/sn/sn-218-26.htm

11. El grupo disciplinar está conformado por los doctores en historia Irma Faviola Castillo Ruiz, Roberto Carrillo Acosta y Francisco Montoya, docentes investigadores de la Unidad Académica de Historia de la Universidad Autónoma de Zacatecas. 
Autos sobre la formación del Cerro Gordo por mandato del conde de Salvatierra, virrey, Pueblo del Tizonazo. (1646, 10 de agosto). Milicias y Guerra, Administración de Milicias. (caja 1, expediente). Archivo Histórico Municipal de Parral, México.

Carrillo Acosta, R. (2013). Ocupación de la Nueva Vizcaya. Los presidios del Camino Real de Tierra Adentro durante los siglos XVII y XVIII (tesis de doctorado sin publicar). Universidad Autónoma de Zacatecas, Zacatecas, México.

Crespo-Francés, J. A. \& Valero M. (1998). Juan de Oñate y el paso del Río Grande. El Camino Real de Tierra Adentro (1598-1998). Madrid, España: Ministerio de Defensa - Secretaría General Técnica.

De Lafora, N. (1939). Relación del viaje que hizo a los presidios internos situados en la frontera de la América septentrional, perteneciente al rey de España. D. F., México: Pedro Robredo.

Fábrica del presidio de Guajoquilla, Guajoquilla. (1784, 31 de diciembre). Colonial, Milicias y Guerra, Habilitación de Milicias. (caja 3, expediente 74). Archivo Histórico Municipal de Parral, México.

Favela González, J. (2003). La lucha agraria en el norte de México. La historia de Pasaje, Durango. Chihuahua, México, Gobierno del Estado de Chihuahua.

Guevara Sánchez, A. (1989). Los atapascanos en Nueva Vizcaya. D. F., México: Instituto Nacional de Antropología e Historia.

Guevara Sánchez, A. (2011). Presidio y población indígena en la Nueva Vizcaya. Siglos XVII y XVIII (tesis de doctorado). Unidad Michoacana de San Nicolás de Hidalgo, México.

Justicia, Fraudes, Ignacio del Horno, en nombre de José de Esparza, contra José Coneto, mercader, por faltar a su confianza en la distribución de géneros que le comisionó, ya que los uso a su favor, Presidio de San Pedro de El Gallo. (1729, 5 de julio). Archivo Histórico Municipal de Parral, México.

Lista de soldados de los presidios de San Felipe y Santiago de Janos, San Pedro de El Gallo y San Miguel del Cerro Gordo, presidio de San Felipe y Santiago de Janos. (1715, 4 de mayo). CoIonial, Milicias y Guerras, Padrón de milicias. Archivo Histórico Municipal de Parral, México.

Martínez, E. (2006). Camino Real de Tierra Adentro. D. F., México: CONACULTA - INAH - Grupo Desea.

Moorhead, M. L. (2012). El presidio (3era ed., G. J. Muñiz y A. Lechuga, Trads.). Chihuahua, México: Gobierno del Estado de Chihuahua.

Muestra de los soldados de los presidios de San Miguel de Cerro Gordo, Nuestra Señora de la Limpia Concepción del Pasaje de Cuencamé, San Pedro de El Gallo, San Felipe y Santiago de Janos, presidios varios. (1725, 5 de enero). Colonial, Milicia y Guerra, Padrones de guerra. Archivo Histórico Municipal de Parral, México.

Muestra de vecinos del real de San José del Parral, valle de San Bartolomé, villa de Santa Bárbara, Pueblo de San Miguel de las Bocas, Presidio de San Francisco de Conchos, real de San Juan Bautista de Indé, minas de Nuestra Señora del Guanaceví, Real de San José del Parral. (1716, 8 de marzo). Colonial, Milicias y Guerras, Padrón de milicias. Archivo Histórico Municipal de Parral, México.

Muestra general de todos los soldados del presidio de Santiago de Mapimí para reconocer si estaban cabales sus plazas y completo el número de su situación, Presidio de Santiago de Mapimí. (1714, 31 de agosto). Colonial, Milicias y Guerra, Padrones de milicia. Archivo Histórico Municipal de Parral, México.

Pucci, F. J. (1993). An historical geography of the north Mexican frontier: the presidio line from 17661786. Ann Arbor, Michigan: University Microfilms International.

Se les comunica a los pueblos vecinos recluten cincuenta indios para emplearse en la fábrica material del nuevo presidio de San Carlos, San Felipe el Real. (1773, 30 de julio). Colonial, Gobierno, Mercedes. (caja 37, expediente 7). Archivo Histórico Municipal de Chihuahua, México.

Wayne Powell, P. (1982, abril). Génesis del presidio como institución fronteriza, 1569-1600. The Western Historical Quarterly. Recuperado de http://revistas.unam.mx/index.php/ehn/article/viewFile/3309/2864 